CENTRE FOR VOCATIONAL EDUCATION RESEARCH

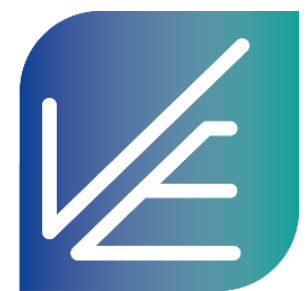

\title{
Closing the Gap Between Vocational and General Education? Evidence from University Technical Colleges in England
}

Stephen Machin, Sandra McNally, Camille Terrier, Guglielmo Ventura

Discussion Paper 031

October 2020 
The Centre for Vocational Education Research (CVER) is an independent research centre funded by the UK Department for Education. CVER brings together four partners: the LSE Centre for Economic Performance; University of Sheffield; National Institute of Economic and Social Research and London Economics.

Any views expressed are those of the authors, and do not represent the views of DfE. For more details on the Centre, go to cver.Ise.ac.uk.

Published by:

Centre for Vocational Educational Research

London School of Economics \& Political Science

Houghton Street

London WC2A 2AE

All rights reserved. No part of this publication may be reproduced, stored in a retrieval system or transmitted in any form or by any means without the prior permission in writing of the publisher nor be issued to the public or circulated in any form other than that in which it is published.

Requests for permission to reproduce any article or part of the Working Paper should be sent to the editor at the above address.

(C) S.J.Machin, S. McNally, C. Terrier, G. Ventura, October 2020 


\title{
Closing the Gap Between Vocational and General Education? Evidence from University Technical Colleges in England
}

\author{
Stephen Machin, Sandra McNally ${ }^{+}$, Camille Terrier ${ }^{\mathrm{x}}$, Guglielmo Ventura^
}

October 2020

\begin{abstract}
Some countries, notably those which have long had a weak history of vocational education like the UK and the US, have recently seen a rapid expansion of hybrid schools which provide both general and vocational education. England introduced 'University Technical Colleges' (UTCs) in 2010 for students aged 14 to 18.48 UTCs are currently open. We use a spatial instrumental variable approach based on geographical availability to evaluate the causal effect of attending a UTC on student academic and vocational achievement and on their labour market outcomes. For those pupils who enter the UTC at a non-standard transition age of 14, UTCs dramatically reduce their academic achievement on national exams at age 16. However, for students who enter at a more conventional transition age of 16, UTCs boost vocational achievement without harming academic achievement. They also improve achievement in STEM qualifications, and enrolment in apprenticeships. By age 19, UTC students are less likely to be unemployed and more likely to study STEM at university.
\end{abstract}

Keywords: technical education; tracking; school value-added

JEL codes: I20, I21, I28

Acknowledgements: We thank the Department for Education for funding this work through the Centre for Vocational Education Research (CVER). We are very grateful for helpful comments from participants at seminars at the Centre for Economic Performance LSE; the Humboldt University of Berlin; the CESifo Economics of Education conference; the International Institute of Public Finance Annual Congress and the 5th IZA Workshop on the Economics of Education. In particular, we would like to thank Bernd Fitzenberger, Eric Taylor, and Barbara Wolfe for helpful comments.

* Department of Economics and Centre for Economic Performance, London School of Economics (Houghton Street, WC2A 2AE, London, United Kingdom). Email: s.j.machin@lse.ac.uk

+ Department of Economics, University of Surrey and Centre for Economic Performance, Centre for Vocational Education Research. London School of Economics (Houghton Street, WC2A 2AE, London, United Kingdom). Email: s.mcnally1@1se.ac.uk

x University of Lausanne. Email: camille.terrier@unil.ch

$\wedge^{\wedge}$ Centre for Economic Performance, Centre for Vocational Education Research. London School of Economics (Houghton Street, WC2A 2AE, London, United Kingdom). Email: g,ventura@1se.ac.uk 


\section{Introduction}

Vocational and technical education provides a solution to two of the most pressing labour market issues of our times: high levels of youth worklessness combined with a shortage of skills in fast-growing technical and professional jobs (OECD, 2017). ${ }^{1}$ Over the 2012-2020 period, nearly two-thirds of overall employment growth in the European Union has been forecast to be in the "technicians and associate professionals" occupational category, which is strongly linked to vocational education (CEDEFOP, 2012). Yet, while investing in high-quality technical education might ease the school-to-work transition, some studies warn against programs that focus too narrowly on technical education as this could hamper workers' ability to adapt to new technologies and change jobs later in life (Hanushek et al, 2017; Hampf and Woessmann, 2017). To find a middle ground that combines general and vocational education, hybrid programs have been developed that provide not only high-quality hands-on technical learning, but also rigorous foundational skills in literacy and numeracy, and hence keep the college doors open (Kreisman and Stange, 2020; OECD, 2014).

A big interest in hybrids that can offer a general and vocational education has recently arisen in countries with weak traditions of providing high quality technical education and training. Part of this reflects recognition of research showing the benefits of having strong and attractive vocational education provision in other countries (see for example Bertrand et al. (2019) for Norway, Fersterer et al. (2008) for Austria, and Alfonsi et al. (2020) for Uganda). Part also reflects that the education policy focus of these countries with a weak technical and vocational tradition has been dominated by the academic route for too long, with rising wage returns to academic education being a key aspect of the increased labour market inequality that has happened over the past forty years (Acemoglu and Autor, 2011). Related to this is the important question of where the technical jobs needed for the future will come from, especially given the hollowing out of middle skill jobs that has occurred through the patterns of job polarization and rising wage inequality (Autor, Katz and Kearney, 2008; Goos and Manning, 2007)

As a consequence, introducing new institutions that jointly offer academic and vocational education has started to become a key part of education provision, especially in the US and UK, two countries that have historically deferred vocational education to post-school provision (Smithers, 2013). ${ }^{2}$ In the US, a growing number of institutions now specialize in 'career and technical education' (CTE). About 8.8 million high school students - nearly half the US high school population - are enrolled in one or more CTE courses. ${ }^{3}$ Similarly, England introduced University Technical Colleges' (UTCs) in 2010. In the words of their co-founder, Kenneth Baker, UTCs 'are 14-18 schools which offer technical subjects taught to a high level

\footnotetext{
${ }^{1}$ In $2019,11.7 \%$ of the youth workforce was unemployed in OECD countries, a number that jumps to $14.3 \%$ for the countries of the European Union, with very high rates in some places like $20.1 \%$ in Sweden, $29.2 \%$ in Italy, and $32.6 \%$ in Spain. The UK has had a persistently high percentage of 16-19 year olds classified as NEETs (not in education, employment or training) by now for several decades. In parallel, some employers cannot fill their vacancies due to a skills mismatch. Among the domains most impacted by shortages are computers and electronics, education and training, math and science, and healthcare (OECD, 2017).

${ }^{2}$ Many European countries, in contrast, have well established tracking systems in secondary school where students select either vocational or academic tracks (OECD, 2010).

3 In New Year City, about 50 of 400 high schools are dedicated exclusively to CTE, nearly half of which are new (Jacoby and Dougherty, 2016).
} 
by experienced professionals' (Baker, 2013). Like their counterparts in the US, UTCs have a (technical) subject specialism (in STEM) but also require all students to meet the same academic standards as in any other school. UTCs also partner with employers and universities to design their curriculum, deliver the teaching, and provide a broad choice of pathways either to university, apprenticeships, or directly to a career. This paper evaluates the causal effect of UTCs on students' achievement and early labour market outcomes.

In the space of a few years, the number of UTCs has grown rapidly in England, reaching 48 schools in 2020. Yet, despite their rapid expansion, various policy reports present a picture of UTC performance that is poor in most respects (e.g. Dominguez-Reig and Robinson, 2018). Many have experienced recruitment and financial difficulties. On average, the students who attend UTCs have not performed well in national exams at age 16. In 2018, one headline indicator was about a fifth lower for students attending UTCs compared to the national average for the national exams at age $16 .{ }^{4}$ This poor performance may either reflect a negative causal effect of UTCs or a negative selection of students into these schools, as students doing badly at their original institution are more likely to switch to UTCs, which focus more on vocational education. This is particularly true for the younger students who enrol at age 14 .

To account for the fact that students who enrol in UTCs might have very different characteristics from the general population, we use the interaction between a student's cohort year and his/her distance to a UTC as a spatial instrumental variable based upon on geographical availability. ${ }^{5}$ This approach takes advantage of two important features of UTCs: anyone is eligible to enrol in the schools, but students living close by are much more likely to enrol; and there are years when students are ineligible due to the timing of the schools' opening. ${ }^{6}$ Our identification is driven by the between-cohort comparison of differences in outcomes between students living closer to a UTC and students living further away. This allows us to provide a set of estimates of the effect of enrolling into a UTC on a range of outcomes, including test scores in the national exam taken by all students in England at age 16 (i.e. the General Certificate of General Education at GCSEs); outcomes at age 18 (i.e. the end of postsecondary education), entry to tertiary education, and early labour market outcomes.

An interesting feature of UTCs is that they offer two entry points: Students can enter UTCs at either age 14 (and spend up to four years in the school) or at age 16 (and stay for two years). This allows us to measure UTCs value-added for these two age groups. There are at least two reasons why UTCs might be less beneficial for age 14 students than for age 16. First, it is not clear a priori what is the best stage to start teaching a mixed curriculum. While earlier introduction of hands-on technical learning might prevent disengagement of less academicallyoriented students, adding technical classes to an already-demanding curriculum (i.e. preparing for high-stakes national exams at age 16) might be too challenging. Second, changing school

\footnotetext{
${ }^{4}$ See for instance the 'average attainment 8 score', shown in Table 11 from the official release by the Department for

Education:https://assets.publishing.service.gov.uk/government/uploads/system/uploads/attachment_data/file/748 503/2018_KS4_statistical_release.pdf

${ }^{5}$ UTCs are not predominantly oversubscribed which rules out using lotteries to estimate their value-added, as has been used in much of the literature about charter schools (e.g. Abdulkadiroğlu et al. 2011; Angrist et al. 2010; Hoxby et al. 2009). The instrument we use is very close in spirit to the one used by Dobbie and Fryer (2011).

${ }^{6}$ Several papers have shown that distance to a new school can influence preferences to attend. Booker et al. (2011), Dobbie and Fryer (2011) and Walters (2018) used this observation in relation to charter schools as well as earlier literature about enrolment decisions (e.g. Card, 1995; Neal, 1997).
} 
at age 14 might be more costly than at age 16 because it is not a common transition time. While age 16 is the time at which students move between lower and upper secondary education in England (often moving institution), it is rare to move school at age $14 .{ }^{7}$ This has been suggested as a reason for why UTCs struggle to recruit enough students and for the lower prior attainment of students who enrol at age 14 compared to age 16 .

We find striking differences in UTC performance for students who enter at age 14 and age 16. For the younger entrants, we find that UTCs do very badly at enabling their students to do well at the national GCSE exams at age 16. Students who enrol in UTCs are 26 percentage points less likely to get at least 5 good grades relative to what they would have achieved in another institution. As a benchmark, this negative effect is equivalent to doubling the achievement gap between disadvantaged and non-disadvantaged students in England. This negative effect is reflected in students' poor achievement in maths and English, whereas UTCs are no worse than other institutions at enabling their students to achieve a good grade in science (i.e. one of their subject specialisms). This poor performance has a high cost because good grades at GCSE are a key precursor to educational progression and positive labour market outcomes (e.g. see Machin et al. 2020).

Interestingly, our results are far more positive for students who enter at age 16. Starting with academic achievement, we find that students who enrol in UTCs are neither doing better or worse in terms of enrolment and achievement at age 18 (A-level), a neutral result which stands in stark contrast to the very negative results for students who enter at age 14. UTCs have a positive effect on achievement of vocational qualifications. Students are 22 percentage points more likely to enter high level vocational qualifications, and 26 points more likely to do well. Enrolling in a UTC also makes entering and achieving STEM qualifications more likely.

We then look at outcomes related to the labour market. Consistent with UTCs' aim to prepare students for the world of work, we find that they significantly increase the probability of starting an apprenticeship, a positive result as apprenticeships have been shown to significantly boost later earnings in England (Cavaglia et al. 2020) and have been shown to ease the school to work transition in many contexts (Wolter and Ryan, 2011). Part of this increase (about 30\%) arises from an increase in apprenticeships delivered by UTC-sponsoring employers, a result that confirms that employers' involvement in running UTCs facilitates apprenticeship matching between students and firms. We also find positive effects of UTCs on higher-education and labour market outcomes. Students who enter UTCs at age 16 are 3 percentage points less likely to be classified as "not in education, training or employment" (NEET) at age 19. They are also much more likely to enter university to do a degree in a STEM subject (by about 20 percentage points), a particularly interesting result given that STEM fields are associated with occupations that have higher earnings (e.g. Kinsler and Pavan, 2015). Although we do not find significant effects on earnings conditional on employment, in general our results are in line with a rich literature that shows positive returns to vocational education (e.g. Alfonsi et al. 2020; Kreisman and Stange, 2020).

\footnotetext{
${ }^{7}$ Unlike the education system in other countries (where middle schools are a much more important part of the institutional setting and where many school pupils attend three compulsory schools over the course of their studies), compulsory education in England is, for the vast majority of pupils, divided into just two sets of schools to be attended: primary schools (age 5-10) and secondary schools (age 11-16). Almost all students remain in the same school for their lower secondary education (between age 11 and 16). At age 16, over half of a cohort move institutions. The fact that the UTC entry points (at age 14 and 16) are aligned with the national system at age 16 but not at age 14 is important for understanding our findings.
} 
We then investigate what is driving the striking differences in UTC performance for students who enter at age 14 and age 16 . We start by comparing the characteristics of the age14 and age-16 compliers (students who are induced to enrol in a UTC by the instruments). We show that students who enrol at age 14 have significantly lower test scores at entry than students who enrol at age 16. We also show that UTCs have a heterogenous effect on high- and lowachieving students: the better the intake, the larger UTC performance. Taken together, these results explain part of UTC poorer performance for age 14 entrants. A back-of-the-envelope calculation shows that, if UTC intake were as good at age 14 as at age 16 , we would no longer observe some of the main negative effects for age-14 students.

The results have important policy implications. If UTCs recruited more able students at age 14, they would enable them to get better results. As noted above, 14 is also an atypical age for transition in England as most students stay in the same school from age 11 to 16 . Our results support moving UTCs' recruitment of young students to common transition times. In line with this suggestion, a number of UTCs have recently begun to change their recruitment age. ${ }^{8}$ Our analysis also shows that UTCs improve after the first year of opening, which suggests caution on making judgements about schools that are brand new and likely to face adaptation costs during the first year.

Beyond its policy relevance in England, our paper contributes to the question of how to best to provide vocational and technical education in a context where labour demand is growing for jobs linked to technical education (as discussed above). Our research is particularly relevant for countries without a well-respected route into vocational education. The US is one such example and is also seeking to undertake a rapid expansion of hybrid academic and technical schools that share important features with the UTC model (such as a focus on STEMs and highdemand skills, and partnerships with local companies and universities). Pinning down the sources of performance and failures of the UTC model is therefore of first-order importance for the development of successful vocational and technical education in the coming years.

This paper contributes to a literature on the efficacy of vocational education (Hampf and Woessmann, 2017; Hanushek et al, 2017; Kreisman and Stange, 2020; Meer, 2007; Mane, 1999). Many papers leverage reforms that have been adopted through the ' 70 s to ' 90 s, usually in the context of the two-track model in which vocational and academic education are distinct and separate and where the latter is ranked more highly (Bertrand et al., 2019; Oosterbeek and Webbink, 2007; Malamud and Pop-Eleches, 2010, 2011; Zillic, 2018; Hall, 2012, 2016). ${ }^{9}$ Our paper differs from this literature in two main respects: We look at a very recent initiative, and instead of comparing vocational and academic education in opposition to each other, we consider a new type of hybrid schools that aim to combine both.

\footnotetext{
${ }^{8}$ In particular, five UTCs among the ones considered in our analysis by now admit students in Year 9 (age 13) and two UTCs have a new entry point at the end of primary school in Year 7 (age 11).

${ }^{9}$ Past reforms are particularly useful to measure the short and long-term returns of vocational education as they leave enough time to measure labor market outcomes of the students who were exposed to the reform. Papers have analyzed the effects of reforms in Romania (Malamud and Pop-Eleches, 2010, 2011), Croatia (Zillic, 2018), the Netherland (Oosterbeek and Webbink, 2007), and Sweden (Hall, 2012, 2016). Bertrand et al. (2019) evaluate a reform in Norway that involves integration of more general education into the vocational track, easier transfers between tracks, and addition of six-month supplementary academic degree to increase access to college. Another very relevant strand of literature has analyzed the effect of participation in "School-to-Work" programs (Cellini, 2006; Neumark and Rothstein, 2006).
} 
By placing a focus on schools instead of tracks, our analysis also contributes to the literature on the value added of a new type of educational institution such as charter schools in the US, academies in England, or free schools in Sweden (e.g. see Epple and Romano, 2015 and Abdulkadiroğlu et al. 2011 for the US; Eyles and Machin, 2019 and Eyles et al., 2018 for England; Bolhmark and Lindahl, 2015 for Sweden). However unlike many of these new schools, UTCs are not over-subscribed, which rules out using admission criterion or lotteries to measure their value-added. How to evaluate the effectiveness of new schools that are not immediately very popular (and therefore not over-subscribed) is an important methodological question to build a comprehensive picture of schools effectiveness. We build and develop a modelling framework that enables us to evaluate the effectiveness of new institutions that are under-subscribed.

This paper relates to the literature in the US that evaluates the effectiveness of Career and Technical high schools and Career Academies. Recent studies commissioned by the US Department of Education has found mixed evidence of the effects of these schools on secondary, postsecondary, and labor market outcomes (U.S. DOE, 2012). Dougherty (2018) studied three career academies in Massachusetts that volunteered to be evaluated and finds large high school graduation effects from students who are just accepted into the schools compared with those who just miss the cutoff. Brunner et al. (2019) evaluate the effect of admission to 16 stand-alone technical high schools within the Connecticut Technical High School System. Using information on admission scores and a regression discontinuity approach, they find positive effects on high school graduation but negative effects on college enrollment. Our paper complements this literature by providing the first evaluation of a largescale and nationwide introduction of hybrid schools that combine vocational and academic education.

The remainder of this paper is structured as follows. In Section 2, we describe the English Education system and the role of University Technical Colleges. In Section 3, we describe the data and we set out the methodology in Section 4. In Section 5, we explain the main results and then in Section 6, we consider various mechanisms that may explain our findings. This includes considering how effects are influenced by the characteristics of the complier groups amongst the two entry cohorts. We also explore whether the effects of UTCs are heterogeneous along various dimensions. We conclude in Section 7.

\section{The English Education System and University Technical Colleges}

In England, compulsory full-time education is until the age of 16, with students entering secondary schools from age 11 (see Figure 1). All students undertake exams for the General Certificate of Secondary Education (GCSEs) at age 16. This typically consists of about eight subjects, including English and maths. After this exam, students pursue upper secondary education (16-18) either in the same school or in another institution where they undertake either academic subjects (A-levels), vocational subjects, or some combination. Students who are more academically inclined (and who have sufficiently good grades at GCSE) typically either stay in the same school or move to a Sixth Form College. The other half of the cohort go to a College of Further Education where they usually specialize in a vocational programme of study 
although a minority combine this with academic education (A-levels). ${ }^{10}$ The education system in England is very straightforward for those who go on to the academic track post-16. They study for A-level qualifications and many go to university afterwards. For the other 50 percent, the system is far more opaque as there are many types of educational qualifications and specialisms and not many well-known pathways (Hupkau et al. 2017).

Starting from 2010, 'free schools' have been set up in England. ${ }^{11}$ These are new schools which are set up by non-governmental groups (e.g. charities, trusts etc) and are publicly funded. They are similar to charter schools in the U.S. and free schools in Sweden. University Technical Colleges (UTCs) are a type of free school that are established by employers seeking to fill skills gaps in their local areas. They are publicly funded academies with an age range of 14-19, a longer school day to cover the Science, Technology Engineering and Maths ("STEM") related GCSEs as well as technical qualifications. UTCs teach one or more technical specialism that meet the skills shortages in the region. These include: engineering; manufacturing; computer science; health sciences; digital technologies; and cybersecurity. The UTC governing body is always controlled by local employers and a local university. ${ }^{12}$

Influential policy makers devised the concept of UTCs as a response to the perception that students do not have good enough options to pursue vocational or technical education in England. Although UTCs have a focus on technical education, they are not intended to be purely specialist. Between age 14 and 16, students spend 40 per cent of their time on technical subjects and 60 per cent on other general subjects including English, maths and science. These percentages are reversed from age 16 onwards, with more focus on technical subjects although they continue to study outside the core technical curriculum, having the opportunity to study A-levels and develop wider employability skills (Baker, 2013).

UTCs recruit at age 14 and 16 (Years 10 and 12 respectively). These coincide with particular phases within the National Curriculum: In Year 10, students enter the Key Stage 4 phase of education, which ends at the end of Year 11 with GCSE exams. ${ }^{13}$ Year 12 is the first year of post-compulsory education which normally lasts for two years, between the age of 16 and 18. The first entry point into a UTC (at age 14) is not a time where students typically make a transition to a new school. Most students stay in the same secondary school between age 11 and 16. As described above, at age 16, all students move to a new stage in their education, which may or may not involve moving to a new educational institution.

There are currently 48 open UTCs, with ten others having closed or changed status. Any consortium of individuals or institutions may apply to set one up. ${ }^{14}$ Yet, despite its fast expansion, the new model has been dogged with controversy (see e.g. Dominguez-Reig and Robinson, 2018 and Thorley, 2017). UTCs have been criticized for their poor performance in national examinations. Some of this has been borne out by evaluations of Schools Inspectorate (OfSTED): On average UTCs lag behind state-funded mainstream institutions in terms of overall effectiveness (Dominguez-Reig and Robinson, 2018). Recruitment at age 14 has also

\footnotetext{
${ }^{10}$ Colleges of Further Education are very different from UTCs in being much larger institutions (more like universities than schools) who cater for both young and adult learners and unlike UTCs do not have a specific mission with regard to STEM specialism and the integration of academic and vocational study.

${ }^{11}$ Under the same government, most secondary schools (age 11-16 or 11-18) have become 'academies' meaning that they are more autonomous from central and local government than previously.

${ }^{12}$ For more information, see their website: https://www.utcolleges.org/the-utc-story/

${ }^{13}$ There is no grade repetition in the English system.

14 The application process is described here: https:/www.gov.uk/government/collections/opening-a-utc
} 
proven very challenging, with all UTCs opened by January 2019 operating at an average capacity of $45 \%$ (NAO, 2019). This has been linked to the non-conventional entry point and lack of publicity: parents might not know about this new type of school opening in the area and existing schools have no incentive to inform them about new competitors. Furthermore, sending their children to a school that specializes in vocational education goes against the grain of a society that tends to value academic education more highly. For a number of UTCs, the low number of students enrolled translated into poor financial viability: in the academic year $2015 / 16,63 \%$ of UTCs were in deficit with a cumulative net loss of $£ 6.3 \mathrm{M}$ (NAO, 2019).

Of course, part of the poor performance of UTCs might be due to the initial low educational level of the students they enrol. The purpose of this paper is to address this potential negative selection so as to identify the causal effect of UTCs on students' achievement. Yet, when doing so, the fact that UTCs are heavily under-subscribed means that we cannot use admission criteria or lotteries as a source of quasi-random admission to a UTC. ${ }^{15}$ This raises the interesting methodological question of how to evaluate the effectiveness of new schools that are not immediately very popular (and therefore not over-subscribed). This is an important question if we want a comprehensive picture of schools effectiveness that is not limited to very popular (and most likely higher performing) schools. We design a methodology that allows to evaluate school value added in contexts in which new schools are undersubscribed.

\section{Data and descriptive statistics}

We use administrative data on the census of students attending state schools in England (the National Pupil Database) linked to data on their later educational outcomes at the age of 16 and $18 .{ }^{16}$ The former is when they do their GCSE exams. The latter is the attainment of further education outcomes (A-levels or the vocational equivalent). We also consider whether students commence an apprenticeship. Finally, for some cohorts of students, we can look beyond secondary education and consider the following outcomes at the age of 19: whether they remain in education; start a university degree; start a university degree in Science, Technology, Engineering or Maths (STEM); are classified as 'not in education, employment or training' (NEET); annual earnings after one year (if in employment). Information on participation into Higher Education comes from the Higher Education Statistics Agency data whereas information on labour market participation and earnings is gathered from tax records linked to education administrative data (Longitudinal Education Outcomes). In addition to information on the educational institution attended and later educational outcomes, we also have data on prior attainment in national tests (e.g. at age 11), the school previously attended, demographics (gender; ethnicity; free school meal eligibility; language spoken at home) and their home post-code, an important variable to construct the distance between each student's home and each University Technical College.

There are two potential entry points at UTCs: at age 14 (Year 10) or age 16 (Year 12). We use cohorts of students in Years 10 and 12 between academic years 2009/10 and 2014/15.

\footnotetext{
${ }^{15}$ Abdulkadiroğlu et al. (2016) used a grandfathering instrument to estimate the value-added of charter schools without lotteries. Yet, this instrument can only be used when traditional public schools convert to a different school type (charter schools in their case). It cannot be used for brand new schools.

${ }^{16}$ Outcomes at age 18 can be ascertained by administrative data in the Individual Learner Record and Key Stage 5 results. These data sets are all linked with the National Pupil Database.
} 
At this stage, there were 30 UTCs open with a Year 10 intake and 29 UTCs with a Year 12 intake. For students entering in Year 10, we focus on outcomes at age 16 (i.e. GCSEs) whereas for those entering in Year 12, we focus on outcomes at age 18 and $19 .{ }^{17}$

Figure 2 shows where UTCs considered in our analysis are located in England. Most students live too far from a UTC to enrol in one. This is reflected in the relationship between distance and the probability of enrolling in a UTC: Figure 3 shows that the probability of enrolling in a UTC predictably declines as students live further away from one. By the time one gets to about $20 \mathrm{~km}$ from the UTC, the probability of attendance is almost negligible. Accordingly, we confine our initial sample to all students within the $90^{\text {th }}$ percentile of the home-to-UTC distance distribution for those attending UTCs. In the case of those entering in Year 10, this corresponds to $20 \mathrm{~km}$ whereas for those entering in Year 12, it is $23 \mathrm{~km}$. Based on this definition, about half of students are not within reach of any of the UTCs we consider in this analysis and are dropped from our sample. Most others are near 1 or 2 UTCs.

Those attending UTCs do not look anything like the average student in our sample. This is not surprising given that UTCs, with their specialist approach, will not necessarily be attractive to the typical student. This can be seen in the left-hand side of Table 1, which reports summary statistics of students who attend UTCs compared to those who do not. The upper panel of Table 1 shows that $76 \%$ of students enrolling in UTCs in Year 10 are male as opposed to $51 \%$ for non-UTC students. UTC students are also more likely to speak English as a first language - $91 \%$ of students in UTCs compared to $71 \%$ among non-UTC students. They are more likely to be white British and less likely to be amongst the poorest students (i.e. they are less likely to be eligible to receive free school meals compared to those not attending UTCs). Those attending UTCs have much lower prior attainment in English (they scored 0.20 standard deviations lower than non-UTC students in the national test at age 11) but are more similar with regard to prior attainment in maths.

Similar differences emerge among Year 12 students for most of the variables: $81 \%$ of UTC students are male and $90 \%$ speak English as a first language compared to $75 \%$ of nonUTC students. However, in contrast to Year 10 students, UTC students are better performing in terms of prior attainment in maths than non-UTC students (i.e. 0.20 standard deviations higher in the national test at age 11) and not quite as much worse at English (i.e. a difference of about 0.08 standard deviations). Such differences in who selects to attend a UTC are not surprising given UTCs known focus on STEM and vocational courses.

\section{Methodology}

\subsection{Instrumental Variables}

The primary empirical challenge to identify UTC effectiveness is the non-random selection of students into UTCs. The descriptive statistics show that students who attend UTCs differ in a number of ways from the general pool of students, a fact that may bias naive comparisons of UTC and non-UTC students. For identification, we use an instrumental variable approach. The instruments are interactions between a student's cohort year and a home-to-UTC

\footnotetext{
${ }^{17}$ For the post-18 analysis we need to exclude the cohort of Year 12 students in academic year 2014/15: these students turn 18 after 2016 but data on higher-education participation and labour market is only available until academic year 2015/16.
} 
continuous distance variable. Because the regression controls for cohort fixed effects and UTCby-distance effects, identification is driven by the between-cohort comparison of differences in outcomes between students living closer to a UTC and students living further away. If the interaction between a student's distance to a UTC and cohort only affects his or her achievement through its effect on enrolment in the UTC, this identifies the causal effect of attending a UTC on later outcomes.

In other words, we rely on two main sources of variation in the probability to enrol in a UTC (and in outcomes). First, we compare outcomes between students living at a given distance to a UTC after its opening (these students were eligible to enrol) and students living at the same distance of the same UTC but before the opening (these students were not eligible to enrol). Second, we compare the outcomes of students from the same cohort living further away from the UTC in order to adjust for year-to-year variation that may affect all students independently of where they live. ${ }^{18}$ The source of identification used in this paper is very similar in spirit to that used by Dobbie and Fryer (2011) to evaluate the Harlem Children Zone, except that we use a continuous definition of distance and take advantage of the additional differences that exist between the 30 different UTCs.

2SLS regression. The causal relation of interest is captured using the following equations for outcome $Y_{\text {iut }}$ of student $i$ living in the proximity of UTC $u$ in academic year $t$ :

$$
Y_{i u t}=\alpha_{t}+\boldsymbol{\beta} U T C_{i u t}+\sum_{j} \gamma_{j}\left(U_{j} D_{i u}\right)+\delta^{\prime} X_{i}+\varepsilon_{i u t}
$$

$Y_{\text {iut }}$ denotes either education attainment measures or post-18 outcomes (for cohorts that enter UTCs at age 16). The variable $U T C_{i u t}$ indicates whether a student is enrolled in a UTC and $\beta$ identifies the causal effect of UTC enrolment on each outcome measure. The term $\alpha_{t}$ denotes cohort fixed effects, which captures different cohorts of students who might be eligible to enrol in each UTC. The dummies $U_{j}$ are indicators for UTC fixed effect (indexed by $j$ ), which are interacted with a continuous distance variable $D_{i u}{ }^{19}$ ands $X_{i}$ is a vector of demographic controls with coefficient $\delta$. Controls include prior attainment at age 11, gender, ethnicity, whether eligible for free school meals, and whether English is spoken at home. $\varepsilon_{i u t}$ is an error term. The first-stage equation for IV estimation takes the form:

$$
U T C_{i u t}=\lambda_{t}+\sum_{j} \mu_{j}\left(U_{j} D_{i u}\right)+\sum_{j} \sum_{t} \boldsymbol{\pi}_{j t}\left(U_{j} D_{i u} \lambda_{t}\right)+\rho^{\prime} X_{i}+\eta_{i u t}
$$

As in Equation 1, the terms $\lambda_{t}$ and $U_{j} D_{i u}$ are cohort fixed-effects and UTC-by-distance interactions, while $X_{i}$ is a vector of demographic controls, and $\eta_{i u t}$ is an error term. The instrumental variables are interactions between the UTC-specific distance $\left(U_{j} D_{i u}\right)$ and the

\footnotetext{
${ }^{18}$ Distance from schools alone has often been adopted in the literature as an instrument for enrolment decisions (e.g. Card 1995; Neal 1997; Booker et al. 2011). In our context, however, the exclusion restriction is unlikely to hold.

${ }^{19}$ In the main specification used throughout the paper, we use a linear distance measure. As a robustness check, we also test a specification with higher order interactions between distance and UTCs, and distance, UTCs and years. In particular, for each UTC, we estimate the distance polynomial that best predicts enrolment. Finally, we also adopt a specification equivalent to the main one but using travel-to-work distance instead of geographical distance. Results are shown alongside the main specification in Tables B1 to B3 in the appendix. For almost all outcomes measures, results are quantitatively very similar.
} 
cohort effects $\left(\lambda_{t}\right) .{ }^{20}$ The coefficients $\pi_{j t}$ capture the effect of each instrument on enrolment in a UTC.

Sample of potential applicants to UTCs. It is important for us to identify a sample of potential applicants to UTCs before applying the IV method. This is to prevent (i) the first stage from having a very low coefficient and (ii) the standard errors from sharply rising, two concerns which mechanically happen in environments-like ours-where the probability of being treated is very small (Chiburis et al. 2012, Fitzenberger et al. 2016). ${ }^{21}$ Table 1 shows that 3,146 students enroll in a UTC in our initial sample while more than 3 million students do not (meaning that less than one student out of 1,000 enrols in a UTC). In order to reduce imbalance in the number of UTC and non-UTC students in our sample, we estimate the propensity score for UTC enrolment and use it to trim the sample by dropping observations with a probability of enrolling in a UTC that is close to zero. Appendix A provides a detailed explanation of the trimming method. We sketch the key elements in this paragraph.

To estimate the propensity score, we follow Imbens and Rubin (2015) and dynamically identify the group of covariates that predict UTC enrollment. We start by including distance from the UTC and gender, two very strong predictors of enrolment in a UTC (as shown in Table 1). We then progressively include additional covariates such as ethnicity, whether English is spoken as a first language, eligibility to receive free school meals, prior attainment in national tests at age 11 (and at age 16 for Year 12 students), and an array of second order covariates and interactions. Then, we run a logistic regression of UTC enrolment on the final set of variables to compute the propensity score. ${ }^{22}$

Then, following the approach of Crump et al. (2009), we discard all Year 10 students whose propensity score is lower than $0.000751^{23}$ thus limiting our estimation sample to students with a predicted probability of enrolling in a UTC equal to at least 0.075 percent. The figure is very similar for Year 12 entrants among which we discard those whose propensity score is lower than 0.000754 . The resulting trimmed sample includes $1,165,201$ observations for Year 10 students (which is $35 \%$ of the initial sample) and 1,051,450 observations for Year 12 students (29.5\% of the initial sample). The right-hand part of Table 1 shows that students' characteristics are significantly more balanced in the trimmed sample compared to the initial sample (i.e. the second panel compared to the first panel) and Figure 4 plots the distribution of the linearized propensity score for UTC and non-UTC students. This figure confirms the extent of the imbalance between these two groups before the trimming procedure.

We run all 2SLS regressions on the trimmed sample and weight the observations using inverse propensity score weights. Using the weights is important for reducing imbalance in the number of UTC and non-UTC students. Indeed, even after trimming the sample, only 0.2 percent of students attend a UTCs, which is still a small fraction of the potential population. In

\footnotetext{
${ }^{20}$ In practice, we have 51 instrumental variables. This follows from having 30 (29) UTCs for Year 10 (12) that were open for one to five years depending on their year of opening (and for some their year of closure).

${ }^{21}$ Chiburis et al. (2012) show that the use of linear IV estimators with covariates can lead to extremely high standard errors because the asymptotic variance of the IV estimator increases as the treatment probability moves away from 0.5 . For instance, in their simulations, a treatment probability of 0.1 is associated with confidence intervals of the IV estimate that are too large for any meaningful hypothesis testing.

${ }^{22}$ We do this separately for Year 10 and 12 entry groups.

${ }^{23}$ The approach would also lead us to discard observations with a propensity score of above 0.99925 . However, no observation in our sample has such a high estimated propensity score so we only discard observations in the lower tail (as depicted by Figure 4).
} 
contrast, in the weighted sample, the ratio of treated / controls is equal to 1.01, which is equivalent to a 50 percent chance to enrol in a UTC. ${ }^{24}$

Finally, note that the two-steps process we adopt - trimming followed by IV - bears some resemblance with the lottery method used to measure the effect of charter schools in the U.S (see Abdulkadiroğlu et al. 2011 for instance). Several papers start from the sample of applicants to charter schools (instead of using the universe of students) and use the lottery as a source of random selection into charter schools. In our case, we cannot use the sample of UTC applicants because most UTCs are undersubscribed. Instead, we use the trimming process to restrict the sample to students who have a non-zero chance of enrolling in a UTC.

First stage results. Figures $5 \mathrm{a}$ and $5 \mathrm{~b}$ present first-stage results. We regress an indicator for UTC enrolment on controls for prior attainment at age 11, gender, ethnicity, whether eligible for free school meals, and whether English is spoken as a first language, cohort effects, UTC-by-distance effects, and our set of instruments: the interactions between cohort and UTCby-distance effects. The regression for Year 12 students also controls for GCSE test scores. The coefficients on our excluded instruments - the interactions between year and UTC-bydistance effects - are positive and statistically significant for nearly all of the years when students are eligible for a UTC, indicating that chances of enrolling in a UTC increase more after the opening for students who live close to a UTC than for students who live further away. 39 instruments out of $51(76 \%)$ are significantly different from zero at the $95 \%$ confidence level for the Year 10 students and 42 out of 51 (82\%) for the Year 12 students. ${ }^{25}$ Given the relatively large number of instruments, this is reassuring as it rules out concerns about weak instruments. We test the null hypothesis that the excluded instruments are jointly equal to zero using the F-test. This is strongly rejected for both the Year 10 and Year 12 regressions.

Identifying assumptions. The key identifying assumption of our method is that the interaction between a student's distance to a UTC and cohort only affects student outcomes through its effects on the probability of enrolment in a UTC and not through any other unobserved characteristic. This assumption allows unobserved characteristics of students to vary with distance to a UTC as long as such differences are assumed to evolve in the same way between cohorts. This assumption would be violated if, for example, parents were to selectively move closer to a UTC in the years after its opening based on unobservable characteristics. This is unlikely given that UTCs are not oversubscribed and all students, regardless of their address, are eligible to enrol without parents having to strategically move closer to fall within a catchment area and enhance chances of admission. More generally, UTCs had only opened recently, leaving little time or incentive for parents to undertake the time-consuming business of moving to a new house. ${ }^{26}$

\footnotetext{
${ }^{24} \mathrm{We}$ also test an alternative to inverse propensity score weighting, in which we run standard (unweighted) 2SLS regressions on a matched sample of UTC and non-UTC students. To rebalance the sample, for each UTC student, we keep the closest non-UTC student in terms of estimated propensity score (using the nearest neighbour matching routine). We do the matching without replacement and using the same propensity score used in the weighted 2SLS regressions. The results obtained are quantitatively similar and are reported in Tables B4 to B6 in the appendix.

${ }^{25}$ The first stage of the 2SLS approach is very strong with a high F-statistic. The F-statistic is in excess of 10,000 for the Year 10 entry cohort and even higher for the Year 12 entry cohort. Our results are very similar when weak instruments are omitted.

${ }^{26}$ For our cohorts of interest only 4 UTCs had been open long enough for parents to observe the outcomes of the first intake of students.
} 
To test whether variation in the instrument is associated with changes in students' observed characteristics, we perform a balance test in which we regress individual characteristics on UTC enrolment, which we instrument as in equation 2. A small and insignificant coefficient would suggest that students induced into enrolling in a UTC by variation in the instrument do not differ in terms of pre-determined characteristics (and hence lends credence to the independence assumption). ${ }^{27}$ Table 2 reports the results of this balance test for the following characteristics: being eligible to receive free school meals (FSM), prior attainment in national tests of maths and English at age 11, and prior attainment at 16 (only for Year 12 entrants). The results rule-out compositional changes along these dimensions lending support to our identification assumptions.

Another key assumption is that the propensity scores (that we use to weight each observation) are independent from the instruments. Indeed using weights would raise a concern if they were correlated with the instruments, as this would affect the 2SLS estimates. To offer reassurance that weighting is not driving our IV results, we use the same balance test as for students' characteristics and test whether students induced into enrolling in a UTC by variation in the instrument differ in terms of the propensity score. The last column of Table 2 shows that this is clearly not the case. This independence between the propensity score and the instrument is not surprising for two reasons. First, because the propensity score is a linear combination of pre-determined characteristics, the test we perform can be seen as a comprehensive balance test that just confirms the balancing results we find on students characteristics taken separately. Second, and perhaps most importantly, the propensity score uses students' distance to a UTC as a predictor of UTC enrolment whereas our instruments rely on the variation over time in how distance predicts enrolment in each UTC. We deliberately do not use any interaction between distance and cohorts to predict the weights.

\section{Results}

We present the main estimates of the effect of UTC enrolment on educational outcomes for those entering UTCs at two different points: those entering in Year 10 at age 14 - for whom results at the end of Year 11 (GCSEs) are relevant ${ }^{28}$ - and those entering in Year 12 at age 16 - for whom results at the end of Year 13 are relevant. For the latter group, we also consider higher education and early labour market outcomes for all but the most recent cohort.

\subsection{The Effect of UTCs on Year 10 Entrants}

Table 3 reports the OLS and 2SLS estimation results for the main outcomes students are expected to achieve in the national examinations at age 16 (GCSEs), namely whether the student achieved at least 5 "good grades" at GCSE (which corresponds to "Level 2+" in the English system), a "good grade" in English (i.e. Level 2+), maths and science respectively, and whether the student achieves at least two good grades in science subjects. The latter is

\footnotetext{
${ }^{27}$ We use this 2SLS estimate for the balance test instead of running a reduced-form regression of student characteristics on the 51 instruments because the latter regression generates as many coefficients as instruments, which makes the balance test less straightforward to interpret.

${ }^{28}$ There are not enough UTCs open long enough to evaluate their effect on outcomes for those who enter in Year 10 and stay until the end of Year 13.
} 
particularly relevant for UTCs given their specialization in STEM subjects. We find that enrolling in a UTC has a sizeable negative effect on the probability of achieving all these outcomes except for getting a good grade in science.

Progress in English and Math. Enrolling in a UTC makes students 26 percentage points less likely to get 5 or more 'good GCSEs'. This large negative effect is equivalent to doubling the achievement gap between disadvantaged and non-disadvantaged students in England. ${ }^{29}$ Looking at achievement in math and English separately, we find that enrolling in a UTC reduces students' probability of getting a good grade in English by 14 percentage points and in maths by 6 percentage points. Although the magnitude of these effects are very large, they are smaller than the raw differences we observe between UTC and non-UTC students (presented in column 2), which confirms the negative selection of students into UTCs. ${ }^{30}$ Overall, these results suggest that UTCs are very bad at preparing students for academic subjects, which is worrying as poor performance at GCSE has damaging consequences for students' educational progression and for their labour market prospects. There is a strong expectation by policy makers that students should reach a good grade in English and maths. Since 2015, students who fail to get these grades $\left(A^{*}-C\right)$ are obliged to repeat maths and English the following year. Machin et al. (2020) also show that even narrowly missing a grade $\mathrm{C}$ in GCSE English can reduce the probability of enrolling in upper secondary education by 9 percentage points and the probability of enrolling in tertiary education by 4 percentage points.

Progress in Science. The results in science are less negative. Enrolling in a UTC does not reduce the chances of getting a good grade in science or to achieve at least two good grades in science subjects. ${ }^{31}$ Thus, it appears that UTCs are no better than other institutions in helping students to achieve a good grade in science. This is particularly disappointing as science is one of their core specialisms and a selling point for UTCs. It also lays the ground for technical subjects studied in post-16 education.

\subsection{The Effect of UTCs on Year 12 Entrants}

Students who enter a UTC at age 16 start in Year 12 which corresponds to the beginning of post-compulsory education. They face a variety of options in that year. As discussed in Section 2, students who pursue an academic education will often only pursue A-levels whereas students on a vocational trajectory will pursue either vocational qualifications (of which there are many) or a combination of A-levels and vocational qualifications.

In Table 4 we consider the effect of UTCs on the following outcomes: whether they enter at least one A-level; whether they achieve an A-level; whether they enter at least one vocational qualification at Level 3 (i.e. the same level as A-levels) and whether they achieve a vocational Level 3 qualification; whether they enter any STEM qualification (i.e science,

\footnotetext{
${ }^{29}$ Disadvantage is measured by eligibility to receive free school meals. Achievement is measured by the probability of achieving 5 GCSEs with good grades including in English and maths.

${ }^{30}$ The 2SLS estimates are also usually smaller than the OLS estimates on the trimmed sample, suggesting that students are not only negatively selected into UTCs based on their observed characteristics (such as previous test scores) but also based on their unobserved characteristics (such as motivation).

${ }^{31}$ Results are very similar if we use driving distance instead of geographical distance as our measure of proximity to the UTC.
} 
engineering or maths) and whether they achieve any STEM qualification; whether they start an apprenticeship.

Effect on academic qualifications. We find that UTCs have no effect on students probability of entering at least one A-level and on their probability of achieving at least one Alevel (and the same is true if we consider whether they achieve A-levels conditional on enrolment). ${ }^{32}$ This neutral result on academic achievement for students who enter UTCs at age 16 stands in stark contrast with the very negative results we found for students who enter at age 14. We provide some explanations for these differences in the next section.

Effect on vocational qualifications. Moving to vocational qualifications, we find a positive effect of UTCs: UTC students are 22 percentage points more likely to enter Level 3 vocational qualifications, and 26 percentage points more likely to achieve these qualifications. The larger coefficient on achievement than on enrolment suggests that the effect of UTCs on achieving Level 3 vocational qualifications is driven both by encouraging more students to enter for these qualifications and enabling them to succeed conditional on entry - where the former is the larger effect. We also see this if we consider the probability of achieving Level 3 vocational qualifications conditional on enrolment. Overall, these findings show that UTCs successfully meet their objective of encouraging students to pursue vocational education at advanced level, and perhaps most importantly, that this does not come at the cost of a lower quality of their academic education.

Effect on STEM qualifications. Students attending UTCs become much more likely to enrol in high-level STEM courses. Specifically, students are 24 percentage points more likely to enter and achieve any type of Level 3 STEM course. The similar effect we find on enrolment and achievement suggests that UTCs do very well at encouraging students to enrol in STEMs courses, but do not boost achievement conditional on enrolment (i.e. they are not necessarily better at teaching such subjects than other types of institution).

Effect on apprenticeships. Furthermore, UTCs aim to prepare students for the world of work rather than only to prepare them for skills that can be tested in exams. As reported at the bottom of Table 4, we find that students who enrol in UTCs are 14.5 percentage points more likely to start an apprenticeship compared to if they had enrolled in another institution. This is a very high effect in a context where 23 percent of the sample have started an apprenticeship by this age. It is also notable that the 2SLS point estimate is higher than the OLS estimate in this case (i.e. 0.144 compared to 0.056 ). This is consistent with a story in which UTC students are attractive to employers trying to find an apprenticeship, even after accounting for students non-random sorting into UTCs (based on a predisposition for vocational education for instance).

Apprenticeships (especially at the advanced level) have been shown to positively affect earnings in England (Cavaglia et al., 2020). For UTCs to have an effect on the probability of starting an apprenticeship is thus a very positive outcome. However, one important question is to what extent this is driven by the stronger connections with local employers who sponsor the UTC as opposed to the UTC improving students' employability skills that would be

\footnotetext{
32 All the outcomes related to achievement are measured on the entire student population (rather than the population of students who enrolled in A-Levels, vocational qualifications, or STEM qualification). Our identification method is valid for the entire sample of students, but it may provide biased estimates when applied on a selected sample of students who entered a qualification.
} 
attractive to employers more generally. ${ }^{33}$ Understanding which mechanism prevails has important implications for the success of the UTC model as this is scaled-up or replicated elsewhere: if the UTC curriculum and pedagogical approach fosters employability and softskills then an expansion may lead to an increase in the supply of competent apprenticeship candidates and apprenticeships in general. ${ }^{34}$ On the other hand, advantages of a scaled-up model would be less clear if it is only UTC-sponsoring employers that wish to approach UTC students to fill apprenticeship places.

We distinguish between these two mechanisms by measuring how much of the increase in the probability of starting an apprenticeship arises from an increase in apprenticeships delivered by UTC-sponsoring employers. The last row of Table 4 shows the probability of starting an apprenticeship with one of the employers who sponsor the local UTC: while the baseline probability is not very high, UTC students are $4.1 \mathrm{pp}$ more likely to start an apprenticeship with a UTC-sponsoring employer. This is a substantial effect and accounts for almost $29 \%$ of the overall effect on starting an apprenticeship (14.5 pp). In conclusion, it appears that while employers' involvement in running UTCs facilitates apprenticeship matching between students and firms, UTC students are also much more likely to be hired as apprentices by firms with no official connection to the school. This suggests that UTCs may be better than other institutions at increasing students' employability and at supporting them in the process of finding an apprenticeship.

Effect on higher-education outcomes. Table 5 shows results for post- 18 outcomes for all but the most recent cohort (who are too young). In particular, we consider whether students are in some form of education at the age of 19 (one year after leaving school), whether they started a university degree and whether they started a university degree in Science Technology Engineering and Maths (STEM).

There is no effect on the probability of still being in education at age 19 and a positive but statistically insignificant effect on university enrolment. However, we find large positive effects when looking at STEM university enrollment. UTC students are 18 percentage points more likely to enter university to do a degree in a STEM subject, a particularly interesting result given that STEM fields are associated with occupations that have higher earnings, and that STEM degrees are a driver of productivity and economic growth (e.g. Griliches, 1992; Jones, 1995; Peri et al., 2015). Of course, this effect might not sound so surprising given the large increase we find in students' likelihood of entering and achieving high-level STEMs qualifications while in UTCs. We show, however, that the latter mechanical effect explains only $16 \%$ of UTC students' choice of STEM university subjects. ${ }^{35}$ This suggests that UTCs develop students' tastes and interest for STEM subjects, above and beyond their effect on enrolment and achievement in STEM in upper secondary education.

\footnotetext{
${ }^{33}$ Employability skills include both soft-skills required on the job and skills required to go through an application process. The apprentices' hiring process is not dissimilar from a normal job recruitment: writing a CV, responding to a vacancy note, sustaining formal interviews etc. Better support and preparation from the school staff might be another channel via which UTCs' students are more successful in this process.

${ }^{34}$ This would be consistent with cost-benefit models of apprenticeship hiring decisions in which firms are more likely to hire an apprentice if the pool of applicants has higher skills (including soft skills).

${ }^{35} 14.8$ percent of the students who achieve a STEM level 3 qualification choose a STEM degree at university, versus 2.5 percent for students who do not achieve a STEM level 3 qualification, which represents a 12.3 points gap. Enrolling in a UTC increases students' probability of achieving a STEM Level 3 qualification by 24.5 percentage points which would result in a mechanical increase of 3 percentage points in the probability of choosing a STEMs course at university. This represents $16 \%$ the overall effect we observe (of 18.3 points).
} 
Effect on labour market outcomes. Beyond their role in preparing students for Higher Education, post-16 institutions and UTCs are expected to equip non-university-bound students with the skills and attitudes needed for a successful early transition into the labour market. We therefore look at the effect of UTCs on students' labour market outcomes. We use two outcomes: whether students are not in education, training or employment (NEET) and, conditional on being employed (and not in education), their annual earnings at the age of 19. ${ }^{36}$ When we look into this, we find that students are 3 percentage points less likely to be NEET as a result of enrolling in a UTC in Year 12 . Given a baseline average of $7 \%$ this effect represents a $37.5 \%$ drop in the probability of being not employed and not in education one year after students finish school. We investigate whether UTC students who are employed enjoy higher earnings as a result of better technical skills or better matches: we find a positive but insignificant effect of UTCs on earnings among those who are employed and not in education at age 19 .

Taken together, our results suggest that UTCs are effective at facilitating students' early transition into the labour market without penalising students' chances of progressing to higher education. In particular, they greatly enable students' progression to STEM subjects in higher education settings. This seems relatively in line with a rich literature that shows positive returns to vocational education (Kreisman and Stange, 2020).

\section{Mechanisms}

The negative effects of UTCs for students entering in Year 10 might seem puzzling, given their relatively good performance for students entering in Year 12. This section sheds light on the origins of the performance gap between Year 10 and Year 12, looking at the role played by student intake quality. All UTCs are also brand new schools. We investigate how much of the (under-) performance is driven by a potentially steep learning curve from principals and teachers during the first years of opening, and whether the quality of the fallback schools influences UTC performance.

\subsection{Explaining Differences in UTCs Performance for Year 10 and Year 12 students}

Our analysis shows a striking difference in UTC performance for cohorts of students entering in lower secondary school (i.e. at age 14 in Year 10) compared to those entering for post-compulsory education (i.e. at age 16 in Year 12). UTCs dramatically reduce academic achievement for Year 10 entrants in national exams at age 16 (except in science). In contrast, this negative effect on academic achievement disappears for Year 12 entrants, and UTCs even improve vocationally-oriented outcomes. What can explain such differences given that Year 10 and 12 entrants share the same school-leadership, facilities and school-values?

School Switching and Exam Preparation Time. A first potential explanation is that Year 10 entrants are penalised by changing school at an atypical transition point in English

\footnotetext{
${ }^{36}$ We restrict the sample to students who are employed as otherwise we do not observe their earnings. We additionally exclude students in education to avoid measuring earnings accruing from 'student part-time jobs' (which we cannot identify). This inevitably introduces a selection issue which recommends caution in the causal interpretation of the earnings results.
} 
secondary education. ${ }^{37}$ Students usually study in the same secondary school until they take GCSEs at the age of 16; over the years this has resulted in schools spending more time in teaching the GCSE curriculum in order to improve students' (and schools') performance in these exams. ${ }^{38}$ Changing school between Year 9 and Year 10 may therefore disrupt students' preparation for GCSE exams and may not leave UTCs sufficient time (compared to other schools) to teach the curriculum in as much detail. For Year 12 entrants, this risk does not exist as UTCs spend as much time as other institutions in teaching students for age 18 exams (two years). While this explanation may play some role in explaining the difference in outcomes from entering a UTC in Year 10 compared to Year 12, there are other potential explanations (some of which would compound this effect).

Differences in Intakes and UTCs Heterogenous Effects. A potential explanation is that Year 10 and Year 12 UTC students may be very different in terms of their individual characteristics, in particular prior achievement: if the effect of enrolling in a UTC is heterogeneous along any characteristics that differ between these two groups, the differences in UTC performance for these groups might be attributable to this. As reported in Table 2, UTC Year 12 entrants have higher prior-attainment at age 11 than Year 10 entrants and are lesslikely to come from a disadvantaged background. To investigate whether these differences can explain differences in UTC performance, we proceed in two steps.

First, we show that UTC performance is heterogenous by adding an interaction term between UTC enrolment and prior attainment in English (or maths) to Equation (1). Both UTC enrolment and its interactions are instrumented in the same way as in Equation (2). Table 7 reports the coefficient on the interaction term and shows that, for most GCSE outcomes considered, UTCs are more effective for students with high prior attainment in English or math than for students with low prior attainment.

Second, we show that compliers (i.e. students who enrol in UTC as a result of the change in the instruments) have different characteristics in Year 10 and Year 12. Although we do not know who the compliers are, we can estimate their average characteristics using the following equation: ${ }^{39}$

$$
X_{\text {iut }} * U T C_{\text {iut }}=\sigma_{t}+\boldsymbol{\tau} U T C_{i u t}+\sum_{j} \phi_{j}\left(U_{j} D_{i u}\right)+\psi^{\prime} Z_{i}+\omega_{i u t}
$$

where the dependent variable is an interaction term between student $i$ 's characteristic and an indicator for whether he/she is enrolled in the UTC in Year 10 (or 12 respectively). The righthand side is the same as in Equation (1) except that $Z_{i}$ is the sub-vector of $X_{i}$ when excluding the characteristic on the left-hand side. If we then instrument $U T C_{i u t}$ on the right-hand side as in Equation (2), $\tau$ will identify the average of $X$ among compliers enrolled in a UTC. Table 6 reports the estimates for Year 10 and Year 12 students and the difference between both. Year 10 entrants are 4 percentage points more likely to be eligible for free school meals than Year

\footnotetext{
${ }^{37}$ There is evidence of the disruptive effect of schools transition in the U.S. Hanushek, Kain, and Rivkin (2004) estimate that switching reduces math achievement by 0.03 standard deviation on average.

${ }^{38}$ Normally, students spend Year 10 and Year 11 studying in preparation for GCSEs; however, over the years, it has become increasingly common for schools to anticipate the GCSEs curriculum to Year 9 and to cover it in three rather than two years.

39 This approach follows from Abadie (2002); Abdulkadiroğlu et al. (2018) present an interesting application in which they estimate average characteristics of the schools that compliers would have attended if they had not been assigned a voucher to enrol in private schools. For a more general discussion of how to estimate compliers' characteristics, see Angrist and Pischke (2008).
} 
12 entrants. Similar striking differences exist in terms of prior attainment in national tests at age 11 (called KS2): Year 12 entrants are $0.37 \mathrm{SD}$ better in maths and 0.33 SD better in English than Year 10 entrants.

These large intake differences raise an interesting question: How much better would UTC performance be if they had enrolled better students in Year 10? To answer this question, we make a back-of-the-envelope calculation of UTC performance for Year 10 entrants if they had the same characteristics as Year 12 entrants. The last row of each panel in Table 7 reports the counterfactual results in which we equalize Year 10 students' test scores in English and maths to the average test score among Year 12 compliers. This exercise shows that the negative effect on the probability of obtaining Level 2 in English and maths almost completely disappears. The effect on Level 2 in science, on the other hand, would have been very large and positive. Finally, the effect on achieving 5 or more GCSEs with good grades - which, as a reminder, was by far the most negative effect of all - remains large and negative. For this outcome, improving entrants' quality along one dimension would not be enough to counter the negative UTC performance.

Overall, these results provide suggestive evidence that if UTCs' Year 10 intake were as good as their Year 12 intake they would have had more positive effect on students' GCSEs outcomes. A potential explanation for why lower-achieving students struggle in a UTC is that combining the standard academic curriculum (GCSEs) with additional vocational subjects may be too ambitious for them. Newly opened institutions might also not the best place to help struggling students when staff have little knowledge of their background.

\subsection{Time since opening}

All UTCs are brand new schools. During the first months and years of opening, teachers need to learn how to work together, principals learn how to manage their team, and teachers how to adjust their pedagogical methods to the level of their students. All these adaptation costs might be large, and negatively affect UTC performance in early years, particularly their first year of opening. ${ }^{40}$ We test this hypothesis by checking if UTCs start to perform better after their first year of opening. We focus on two main outcomes for Year 10 and 12 respectively: whether students achieve 5 or more good GCSEs (Year 10) and whether students achieve a Level 3 vocational qualification (Year 12).

For 13 UTCs (those opening in September 2014) we observe outcomes for the cohorts enrolled in the UTC's first year of activity; for a further 13 UTCs (those opening in September 2013) we observe outcomes for cohorts enrolled in the first and second year of activity; for 4 remaining UTCs we observe outcomes for up to five cohorts. We leverage these differences to investigate whether outcomes are better for students that enrolled after the UTC had been opened for at least a year. To do so we estimate the following reduced-form version of Equation $(2)^{41}$ :

\footnotetext{
${ }^{40} \mathrm{~A}$ few studies have examined differences in performance between conversion and start-up charter schools in the U.S, finding mixed results (Buddin and Zimmer, 2005). Imberman (2011) finds that schools that begin as charters generate large improvements in discipline and attendance, while no such effect was observed for conversion charter schools.

${ }^{41}$ Under the independence assumptions tested in Section 4.2, the reduced-form coefficients directly relate to the effect of enrolling in UTC $j$.
} 


$$
Y_{i u t}=\theta_{t}+\sum_{j} \chi_{j}\left(U_{j} D_{i u}\right)+\sum_{j} \sum_{t} \xi_{j t}\left(U_{j} D_{i u} \lambda_{t}\right)+\kappa^{\prime} X_{i}+\zeta_{i u t}
$$

We are interested in the coefficients $\xi_{j t}$ of the triple UTC-by-distance-by-year interactions. Because we condition on the interaction between UTCs and distance, these coefficients capture, for each UTC, the effect of time since opening on students' achievement. After estimating the coefficients, we group them by year since opening (from 1 to 4 ), and plot them in the upper panel of Figure 6 for two main outcomes of Year 10 and 12 entrants. We see that UTC performance improves after the first year of activity, especially for Year 10 entrants. To better illustrate this, the red bar represents the average of each performance indicator by year of activity: UTC performance in the second year of activity (measured by students' probability of achieving 5 or more good GCSEs) is on average 0.5 percentage point higher than their performance in the first year. This improvement is partly driven by the very poorperforming UTCs becoming better after one year. For instance, 5 UTCs have coefficients lower than -0.012 in year one, while none have such a low performance in year 2 . The results for Year 12 entrants (plotted in the upper-right panel) show UTC performance does not improve for this group over time. This is not surprising given that UTC performance is initially significantly better for this group.

\subsection{Quality of the Fallback Institutions}

Differences in performance across UTCs could be explained by the quality of the fallback institutions. Our IV estimates capture the causal effect of UTC enrolment relative to the institution that students would otherwise attend. If the quality of these fallback institutions differ across UTCs, this could explain variation in UTC performance. ${ }^{42}$ We verify this by computing the quality of the UTC's neighbouring institutions. ${ }^{43}$ Quality is defined on a scale from 4 (inadequate) to 1 (outstanding) based on inspectorate reports (Ofsted) and we take the average across neighbouring institutions. To relate this measure to UTC effectiveness we use a variation of Equation 4 that gives us a reduced-form estimate of each UTC's performance:

$$
Y_{i u t}=\theta_{t}+\sum_{j} \chi\left(U_{j} D_{i u}\right)+\sum_{j} v_{j} U_{j} D_{i u} * O p e n_{j t}+\kappa^{\prime} X_{i}+\zeta_{i u t}
$$

Compared to Equation (4), we replace the UTC-by-distance-by-cohort triple interactions with a triple interaction of UTC-by-distance and an indicator for whether UTC $j$ is open for that cohort $t$ : this gives us a single reduced-form effect coefficient for each UTC instead of several coefficients with Equation (4). In the middle panel of Figure 6 we plot the coefficients $v_{j}$ (for the same outcomes as above) against the average neighbouring institution's quality. We find little evidence that UTCs perform better or worse if their neighbouring

\footnotetext{
42 Other papers have tested whether the quality of the fallback school could explain the causal effects of programs or schools they evaluate. Abdulkadiroğlu et al. (2018), for instance, estimate characteristics of complier fallback schools and find that the negative effects of Louisiana Scholarship Program (LSP) in the U.S are not due to atypical fallback schools. In contrast to this paper, we only refer to the quality of institutions in an area surrounding a UTC without identifying each UTC compliers' exact fallback institution as often there are several possible alternatives.

${ }^{43}$ When we consider Year 10 outcomes we arbitrarily define neighbouring schools as the schools who fall within $2 \mathrm{~km}$ of the UTCs. For Year 12 outcomes we consider all Post-16 institutions (schools' sixth forms, Sixth Form Colleges or Further Education colleges) within $5 \mathrm{~km}$ of the UTC.
} 
institutions are better: the linear fit shows that for Year 10 and 12 outcomes, the correlation is weak and in opposite directions.

\subsection{Intake Quality}

Finally, we consider the relationship between UTC students' prior attainment and their performance. Results in the previous section point to better results for students with higher prior attainment at age 11 and we would expect this to be confirmed as we look at variation across UTCs. In the bottom panel of Figure 6 we plot the reduced-form estimates of UTC performance - i.e the coefficients $v_{j}$ from equation (4) - against the UTC students' average standardised age 11 test score in English (for the relevant entry group). The linear fit shows that the correlation between prior attainment and the probability of achieving 5 or more good grades at GCSE is positive and relatively strong: a one standard deviation increase in English attainment is associated with a 1.4 percentage points increase in UTC performance. Similarly, among Year 12 entrants, a one standard deviation increase in English attainment is associated with a 1.5 percentage points increase. We obtain similar results when correlating UTC performance with prior attainment in maths as reported in Table B7. This table also provides results for additional outcomes, such as the probability of starting an apprenticeship.

Overall, the UTC heterogeneity analysis points to better performance for UTCs that had a better intake and in the years after the first year of activity, suggesting that UTCs have potential to improve as they mature.

\section{Conclusion}

This paper studies the arrival of a new type of hybrid institutions - the University Technical College - to England's education landscape which began in 2010 followed by their nationwide introduction. The aims of UTCs are to integrate technical, practical and academic learning and create an environment where students can thrive and develop the abilities that industry needs' (Long and Bolton, 2017). Interestingly, there are two different entry points for UTCs: at age 14, which is an uncommon transition time during secondary school, and at age 16, after the end of compulsory education in England, a much more standard transition time.

We find striking differences in UTC performance for these two entry points. For students who enter at the non-standard transition age 14, UTCs have a large detrimental effect on the probability of reaching an acceptable level of English and maths two years later in GCSEs national exams. These results are of great concern because performance at GCSE is crucial not only to continue academic studies, but also for progression within technical education and for the youth labour market (see Machin et al. 2020).

For students who enter at the more conventional transition age 16, however, the results reveal a more positive story. Although UTCs do not improve enrolment or achievement in academic outcomes (A-Levels), they are good at getting students to enrol and achieve well in higher technical programmes and in STEM subjects. In particular, they are good at placing students on to apprenticeships, an outcome that is beneficial for students as high-level technical education and apprenticeships both have high payoffs in the labour market for young people (e.g. see McIntosh and Morris, 2016; Cavaglia et al. 2020). 
With regard to later outcomes, UTCs reduce the probability of being 'not in education, employment or training' (NEET) at age 18, which is important, as youth unemployment has been shown to put people at a high risk of wage scarring effects and crime participation (Gregg and Tominey, 2005; Bell, Bindler and Machin, 2018). Finally, they strongly increase the probability of enrolling in a university degree in a STEM subject, an outcome which has been associated both with higher earnings and with improved productivity and economic growth (see for example, e.g. Kinsler and Pavan, 2015; Peri et al., 2015).

Investigating mechanisms, an important part of the large difference in UTC performance for students who enter at age 14 and 16 stems from differences in initial achievement between these students (which is lower at age 14). In fact, UTCs deliver better performance outcomes for relatively higher achieving students. Moreover, the overall performance of UTCs improves over time. They are all brand new schools and we show that their performance improves after the first year of opening, which suggests a potentially important adaptation and learning phase.

Our results directly contribute to the policy debate on UTCs. Amid fervent discussions on the under-performance of these schools, we provide the first causal evidence on UTC effectiveness. Consistent with the negative selection of students into UTCs, and whilst there are concerns, we show an overall picture that is somewhat less negative than the one that has been depicted so far (e.g. Dominguez-Reig and Robinson, 2018). By identifying several sources of (under-) performance, our analysis also shows in which directions these institutions could improve. It is still early days in the lifetime of University Technical Colleges, but the model has already evolved in directions that are supported by our results. More UTCs move to recruitment at a natural transition point (i.e. at age 11 as well as age 16), which might improve their performance to the extent that they become better able to attract a higher attaining group of applicants. Our results also indicate that UTCs improve with time, which suggests caution in forming quick judgements about the long-term efficacy of the policy.

Moving beyond their policy relevance in England, the results are relevant for other countries that seek to establish similar institutions, notably the US Career and Technical high schools share several important features with the UTC model. They combine technical and general education, and many focus on STEM and high-demand skills, and partner with local companies and universities. Pinning down the sources of performance and failures of the UTC model is therefore of first-order importance for the development of successful vocational and technical education in other countries in the coming years. Finally, and to conclude, we anticipate there being much more research about the kind of vocational education considered in this paper, commensurate with the widespread recognition that provision of quality vocational and technical education is of first order importance for education and for contemporary labour markets across the world. 


\section{References}

Abadie, A. (2002). Bootstrap tests for distributional treatment effects in instrumental variable models. Journal of the American statistical Association, 97(457), 284-292.

Abdulkadiroğlu A, Angrist J, Dynarski S, Kane T and Pathak P (2011). Accountability and Flexibility in Public Schools: Evidence From Boston's Charters and Pilots, Quarterly Journal of Economics, 126: 699-748.

Abdulkadiroğlu A, Angrist J, Hull P, and Pathak P (2016). Charters without Lotteries: Testing Takeovers in New Orleans and Boston. American Economic Review, 106 (7): 18781920.

Abdulkadiroğlu, A., Pathak, P. A., and Walters, C. R. (2018). Free to choose: Can school choice reduce student achievement?. American Economic Journal: Applied Economics, 10(1): 175-206.

Acemoglu, D., and Autor, D. (2011). Skills, tasks and technologies: Implications for employment and earnings. In Handbook of labor economics (Vol. 4, pp. 1043-1171). Elsevier.

Alfonsi, L., Bandiera, O., Bassi, V., Burgess, R., Rasul, I., Sulaiman, M. and Vitali, A. (2020). Tackling Youth Unemployment: Evidence from a Labor Market Experiment in Uganda (2020). CEPR Discussion Paper No. DP14973. Forthcoming in Econometrica.

Angrist J, Dynarski S, Kane T, Pathak P and Walters C (2010) Inputs and Impacts in Charter Schools. KIPP Lynn, American Economic Review, 100: 239-43.

Angrist J, and J-S Pischke (2008). Mostly Harmless Econometrics, Princeton University Press.

Autor, D. H., Katz, L. F., and Kearney, M. S. (2008). Trends in US wage inequality: Revising the revisionists. The Review of economics and statistics, 90(2), 300-323.

Baker, K. (2013), 'The 14-18 pathways', in K. Baker (Ed.). 14-18 A New Vision for Secondary Education. Bloomsbury.

Bell, B., A. Bindler and S. Machin (2018). Crime Scars: Recessions and the Making of Career Criminals. Review of Economics and Statistics, 100(3): 392-404.

Bertrand, M., M. Mogstad, and J. Mountjoy. (2019). Improving Educational Pathways to Social Mobility: Evidence from Norway's “Reform 94”. NBER Working Paper No. 25679.

Booker, K. T.R.Sass, B. Gill and R. Zimmer. (2011). The Effects of Charter High Schools on Educational Attainment. Journal of Labor Economics. 29(2): 377-415.

Bolhmark, A. and M. Lindahl (2015) Independent Schools and Long-run Educational Outcomes: Evidence from Sweden's Large-scale Voucher Reform, Economica, 82: 508-551.

Brunner, E., S. Dougherty, and S. Ross. (2019). The Effects of Career and Technical Education: Evidence from the Connecticut Technical High School System. Annenberg Institute, Brown University. EdWorking Paper No.19-112.

Buddin, R. and Zimmer, R. (2005). Student Achievement in Charter Schools: A Complex Picture, Journal of Policy Analysis and Management 24: (2), 351-371.

Card, D., (1995). Using Geographic Variation in College Proximity to Estimate the Return to Schooling. In L. Christofides, E. Grant and R. Swidinsky (Eds). Aspects of Labor Market Behaviour: Essays in Honour of John Vanderkamp. Toronto: Univ. Toronto Press.

Cavaglia, C., S. McNally, and G. Ventura. (2020). Do Apprenticeships Pay? Evidence for England. Oxford Bulletin for Economics and Statistics (Wiley online library). 
CEDEFOP (2012). Future skills supply and demand in Europe: Forecast 2012, Research Paper No. 26, Publications Office of the European Union, Luxembourg.

Cellini, S. R. (2006). Smoothing the transition to college? The effect of Tech-Prep programs on educational attainment. Economics of Education Review. 25(4): 394-411.

Crump, R.K., V.J. Hotz, G.W.Imbens, and O.A.Mitnik. (2009). Dealing with Limited Overlap in Estimation of Average Treatment Effects. Biometrika 96(1): 187-199.

Chiburis, R., J. Das, and M. Lokshin (2012). A practical comparison of the bivariate probit and linear IV estimators. Economics Letters 117 (3), 762-766.

Department of Education, Office of Vocational and Adult Education. (2012). Investing in America's Future: A Blueprint for Transforming Career and Technical Education, Washington, D.C.

Dobbie W and Fryer R (2011) Are High Quality Schools Enough to Increase Achievement among the Poor? Evidence from the Harlem Children's Zone, American Economic Journal: Applied Economics, 3, 158-87.

Dominguez-Reig, G. and D. Robinson. (2018). UTCs: Are They Delivering for Young People and the Economy? Education Policy Institute report.

Dougherty, S. M. (2018). The Effect of Career and Technical Education on Human Capital Accumulation: Causal Evidence from Massachusetts. Education Finance and Policy. 13(2): 119-148.

Epple, D., R. Romano, and R. Zimmer. (2015). Charter Schools: A Survey of Research on Their Characteristics and Effectiveness. NBER Working Paper 21256.

Eyles, A. and Machin, S. (2019) The Introduction of Academy Schools to England's Education,. Journal of the European Economic Association, 17(4): 1107-1146.

Eyles, A., Machin, S. and Silva, O. (2018). Academies 2 - The New Batch: The Changing Nature of Academy Schools in England, Fiscal Studies, 39, 121-158.

Fersterer, J., Pischke, J. S., and Winter-Ebmer, R. (2008). Returns to apprenticeship training in Austria: Evidence from failed firms. Scandinavian Journal of Economics, 110(4), 733-753.

Fitzenberger, B, Furdas M and Sajons, C. (2016), End-of-Year Spending and the Long-Run Employment Effects of Training Programs for the Unemployed, IZA Discussion Paper No. 10441.

Gregg, P. and E. Tominey (2005). The Wage Scar from Male Youth Unemployment. Labour Economics, 12: 487-509.

Griliches, Z. (1992). Introduction to "output measurement in the service sectors", Output measurement in the service sectors, University of Chicago Press, pp. 1-22. 1

Goos, M., and Manning, A. (2007). Lousy and lovely jobs: The rising polarization of work in Britain. The Review of Rconomics and Statistics, 89(1), 118-133.

Hall, C. (2012). The Effects of Reducing Tracking in Upper Secondary School: Evidence from a Large-Scale Pilot Scheme. Journal of Human Resources. 47(1): 237-269.

Hall, C. (2016). Does more general education reduce the risk of future unemployment? Evidence from an expansion of vocational upper secondary education. Economics of Education Review. 52: 251-271.

Hampf, F. and L. Woessmann. (2017), Vocational vs. General Education and Employment over the Life-Cycle: New Evidence from PIAAC, CAGE Online Working Paper Series. 
Hanushek, E A., J F. Kain, and S G. Rivkin (2004). Disruption versus Tiebout Improvement: The Costs and Benefits of Switching Schools. Journal of Public Economics 88 (9-10): 1721-46.

Hanushek, E A., G. Schwerdt, L. Woessmann and L. Zhang. (2017) General Education, Vocational Education, and Labor-Market Outcomes over the Lifecycle. Journal of Human Resources 52:48-87.

Hoxby, C., Murarka S. and Kang J. (2009) How New York City's Charter Schools Affect Achievement, New York City Charter Schools Evaluation Project, Cambridge, MA.

Hupkau, C., S. McNally, J. Ruiz-Valenzuela, and G. Ventura. (2017). Post-Compulsory Education in England: Choices and Implications', National Institute Economic Review, 240: 42-57.

Imbens, G. W. and D. B. Rubin. (2015). Causal Inference for Statistics, Social, and Biomedical Sciences: An Introduction. Cambridge University Press.

Imberman, S. (2011), The effect of charter schools on achievement and behavior of public school students, Journal of Public Economics, 95(7), 850-863.

Jacoby, T., and S. M. Dougherty (2016). The New CTE: New York City as a Laboratory for America. Manhattan Institute Report 6. March 2016.

Jones, C. I. (1995). R \& D-based models of economic growth, Journal of Political Economy 103(4) 759-784. 1

Kinsler, J. and R. Pavan (2015). The specificity of general human capital: Evidence from college major choice. Journal of Labor Economics 33(4), 933-972.

Kreisman, D., and K. Stange. (2020). Vocational and Career Tech Education in American High Schools: The Value of Depth Over Breadth. Education Finance and Policy, vol 15(1), pages 11-44.

Long, R., and P. Bolton. (2017). University Technical Colleges. Briefing Paper. Number 07250. 8 March 2017. House of Commons Library.

Machin, S., S. McNally and J. Ruiz-Valenzuela. (2020). Entry Through the Narrow Door: The Costs of Just Failing High Stakes Exams. Journal of Public Economics, vol. 190. Forthcoming.

Malamud, O. and C. Pop-Eleches. (2010). General Education vs. Vocational Training: Evidence from an Economy in Transition. Review of Economics and Statistics. 92(1): 43-60

Malamud, O. and C. Pop-Eleches. (2011). School tracking and access to higher education among disadvantaged groups. Journal of Public Economics. 95(11-12):1538-1549.

Mane, F. (1999). Trends in the payoff to academic and occupation-specific skills: the short and medium run returns to academic and vocational high school courses for non-collegebound students. Economics of Education Review. 18(4):417-437.

McIntosh, S., and D. Morris (2016). Labour Market Returns to Vocational Qualifications in the Labour Force Survey. Centre for Vocational Education Research, London School of Economics. Discussion Paper 002.

Meer, J. (2007). Evidence on the returns to secondary vocational education. Economics of Education Review. 26(5):559-573.

NAO (2019). Investigation Into University Technical Colleges. National Audit Office, London.

Neal, D. (1997). The Effects of a Catholic Secondary Schooling on Educational Achievement. Journal of Labor Economics. 15(1): 98-123. 
Neumark, D., and D. Rothstein. (2006). School-to-career programs and transitions to employment and higher education. Economics of Education Review. 25(4): 374-393.

OECD, (2010). Learning for Jobs. OECD Paris.

OECD, (2014). Skills Beyond School Synthesis Report. OCDE Paris.

OECD, (2017). Getting Skills Right: Skills for Jobs Indicators. OCDE Paris.

Oosterbeek, H., and D. Webbink (2007). Wage effects of an extra year of basic vocational education. Economics of Education Review. 26(4):408-419.

Peri, G., K. Shih, and C. Sparber (2015). Stem workers, H-1B visas, and productivity in US cities, Journal of Labor Economics 33(S1), S225-S255.

Smithers, A. (2013), 'Making 14-18 education a reality,' in K. Baker (Ed.). 14-18 A New Vision for Secondary Education. Bloomsbury.

Thorley, C. (2017). Tech Transitions. UTCs, Studio Schools and Technical and Vocational Education in England's Schools. Institute for Public Policy Research.

Walters, C. R. (2018). The Demand for Effective Charter Schools. Journal of Political Economy. 126(6): 2179-2223

Wolter, S.C. and P. Ryan. (2011). “Apprenticeship". In E.A.Hanushek, S. Machin, and L. Woessmann (Eds). Handbook of the Economics of Education. Volume 3: 521-576. Elsevier.

Zilic, I. (2018). General versus vocational education: Lessons from a quasi-experiment in Croatia. Economics of Education Review. 62:1-11. 
Figure 1: English secondary education system

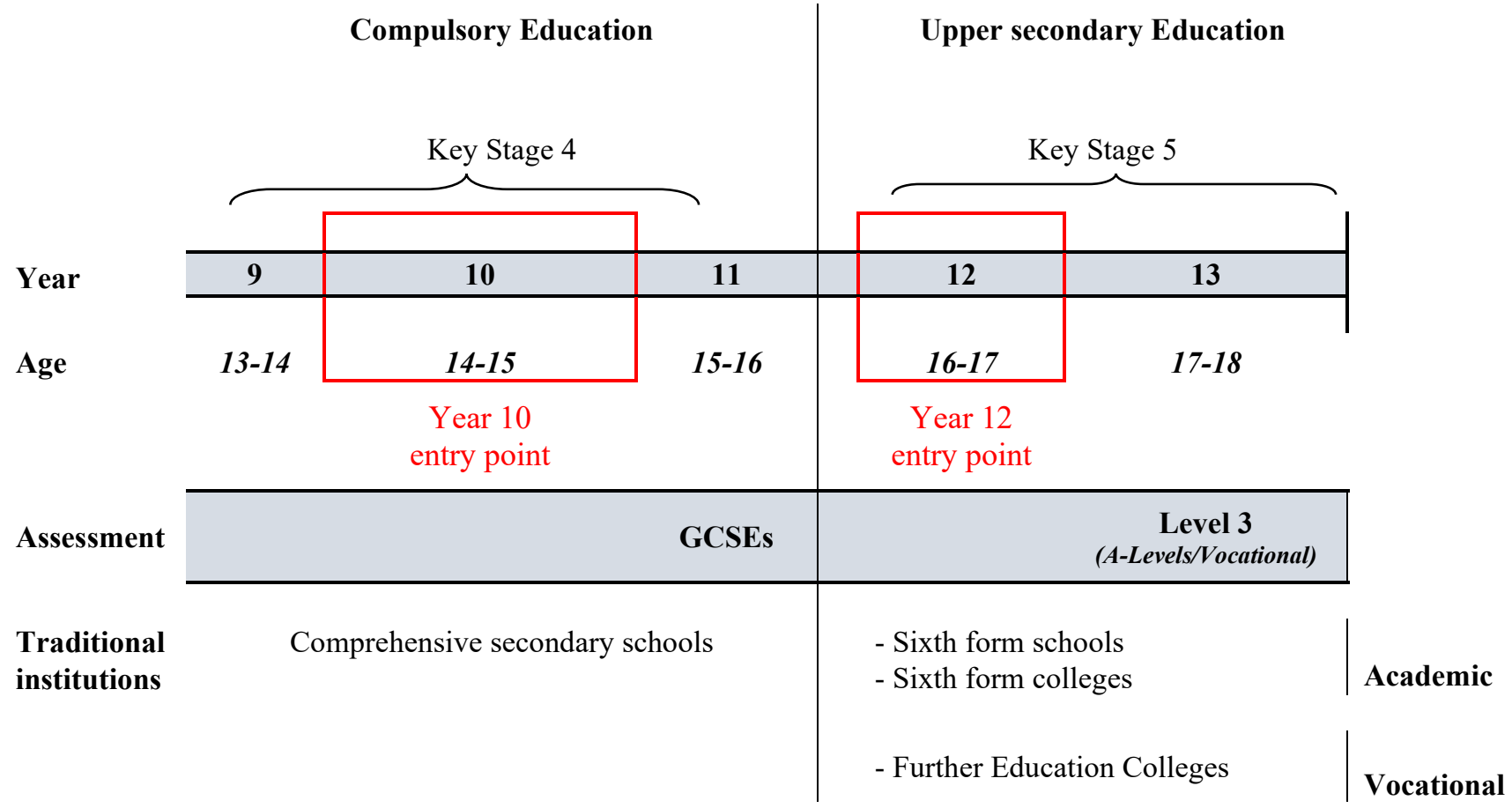

Notes: This figure describes the English education system between Year 9 and Year 13 (age 14 to 18). The two UTC entry point in year 10 and 12 are marked in red. 
Figure 2: UTCs location

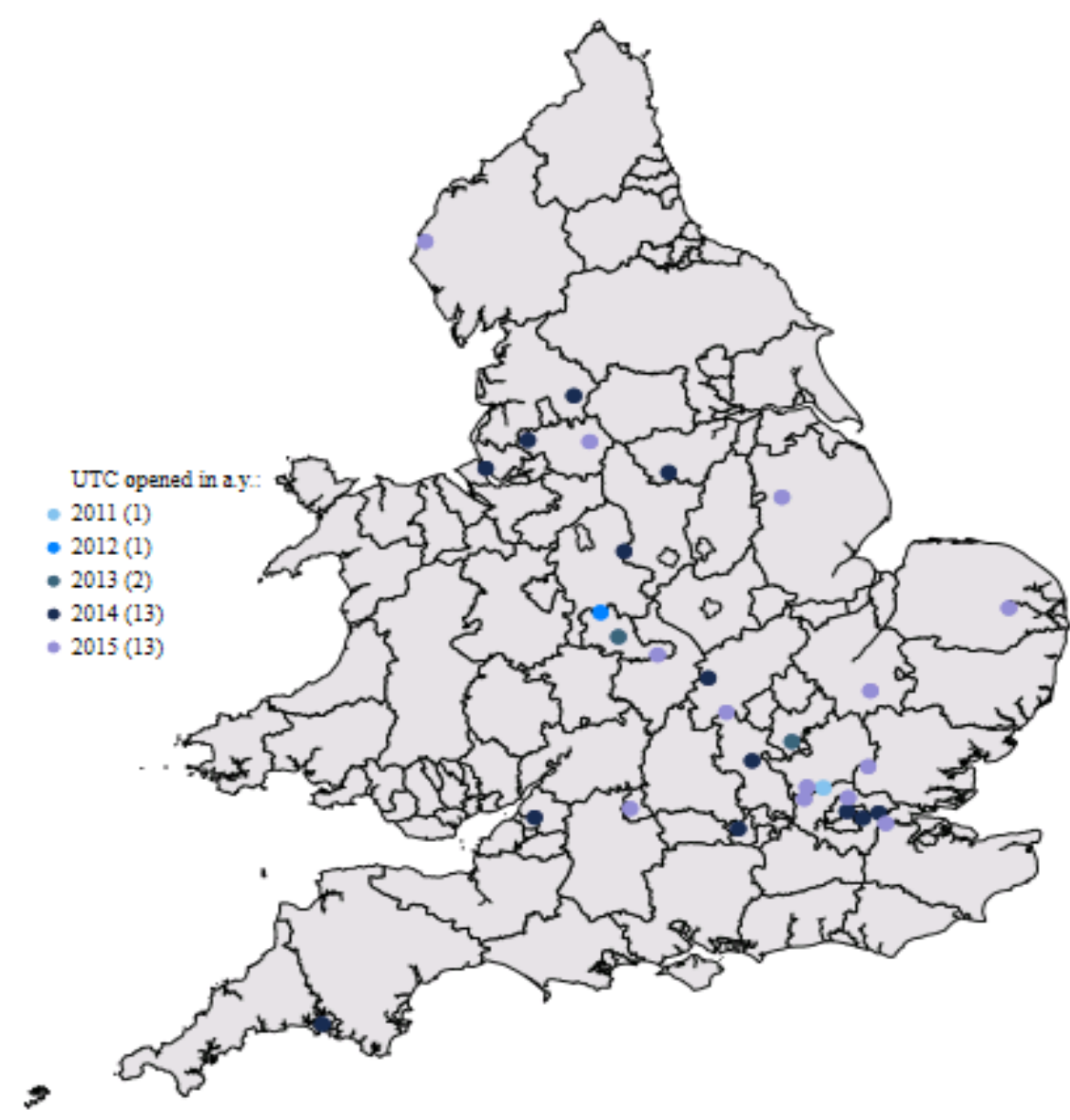

Notes: This figure shows the location across England of the UTCs that opened between academic year 2010/11 and 2014/15. 
Figure 3: Relationship between probability of enrolment and distance from UTC
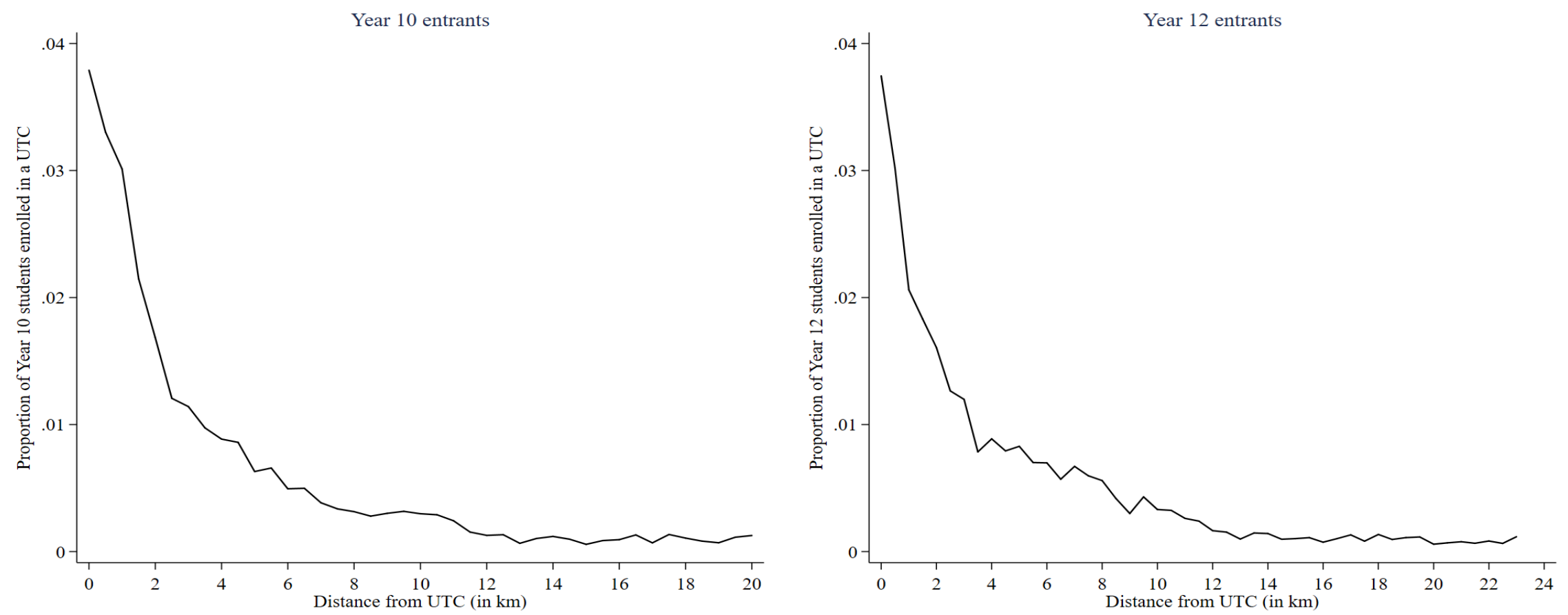

Notes: These graphs show the relationship between distance (in km) from the local UTC and the probability of enrolling in a UTC for both Year 10 and Year 12 entrants. 
Table 1: Descriptive statistics

\begin{tabular}{|c|c|c|c|c|}
\hline & \multicolumn{2}{|c|}{ Initial sample } & \multicolumn{2}{|c|}{ Trimmed sample } \\
\hline & $\begin{array}{c}\text { Non-UTC } \\
\text { students }\end{array}$ & $\begin{array}{c}\text { UTC } \\
\text { students }\end{array}$ & $\begin{array}{c}\text { Non-UTC } \\
\text { students }\end{array}$ & $\begin{array}{c}\text { UTC } \\
\text { students }\end{array}$ \\
\hline & (1) & (2) & (3) & (4) \\
\hline & \multicolumn{4}{|c|}{ I. Year 10 entrants } \\
\hline Distance from UTC & 12.002 & 6.787 & 8.460 & 5.870 \\
\hline White british & 0.585 & 0.702 & 0.768 & 0.707 \\
\hline Male & 0.509 & 0.763 & 0.760 & 0.820 \\
\hline English as first language & 0.711 & 0.910 & 0.913 & 0.923 \\
\hline Free school meal (in Year 10) & 0.211 & 0.157 & 0.138 & 0.149 \\
\hline Maths Key Stage 2 Score (std) & -0.015 & -0.035 & 0.027 & -0.051 \\
\hline English Key Stage 2 Score (std) & -0.019 & -0.210 & -0.149 & -0.266 \\
\hline Propensity score & -8.186 & -5.998 & -9.190 & -8.033 \\
\hline \multirow[t]{2}{*}{ Number of students } & 3345016 & 3341 & 1162328 & 2873 \\
\hline & \multicolumn{4}{|c|}{ II. Year 12 entrants } \\
\hline Distance from UTC & 14.036 & 7.948 & 9.058 & 6.466 \\
\hline White british & 0.617 & 0.696 & 0.761 & 0.693 \\
\hline Male & 0.503 & 0.805 & 0.785 & 0.886 \\
\hline English as first language & 0.749 & 0.901 & 0.911 & 0.903 \\
\hline Free school meal (in Year 11) & 0.185 & 0.110 & 0.099 & 0.107 \\
\hline Maths Key Stage 2 score (std) & 0.008 & 0.204 & 0.249 & 0.222 \\
\hline English Key Stage 2 score (std) & 0.010 & -0.093 & -0.001 & -0.159 \\
\hline Key Stage 4 score (std) & 0.119 & 0.254 & 0.315 & 0.248 \\
\hline Propensity score & -8.325 & -6.071 & -9.170 & -8.024 \\
\hline Number of students & $3,560,293$ & 3,146 & $1,048,873$ & 2,577 \\
\hline
\end{tabular}

Notes: This table reports descriptive statistics for UTC and non-UTC students in the initial sample and in the trimmed sample. Distance is measured in kilometers. Key stage 2 scores are the standardised tests taken by students at the end of primary school (Year 6) while the Key stage 4 score is the aggregate score for the end of secondary school examinations (Year 11). The linearised propensity score is the logarithm of the propensity score estimated in the initial sample. 
Figure 4: Propensity score distribution (Year 10)

Initial sample

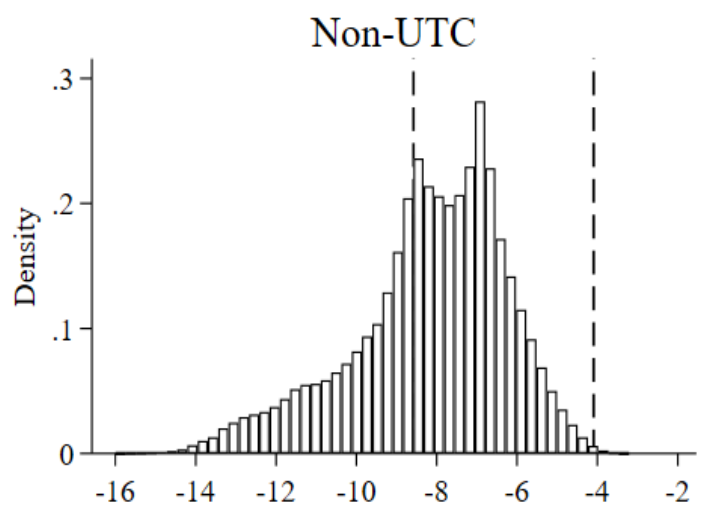

UTC

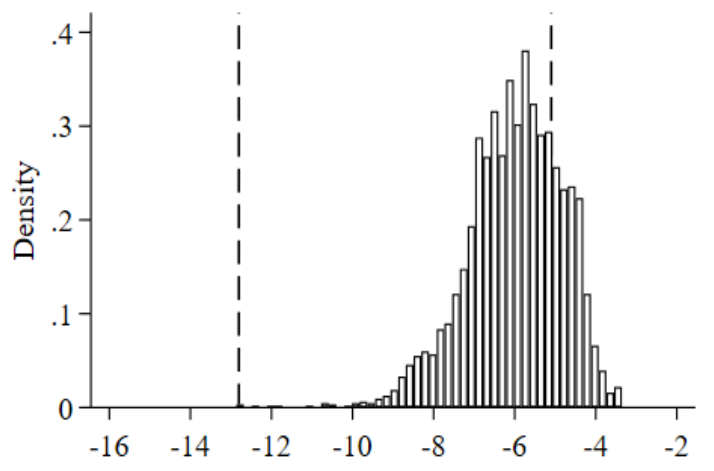

Trimmed sample

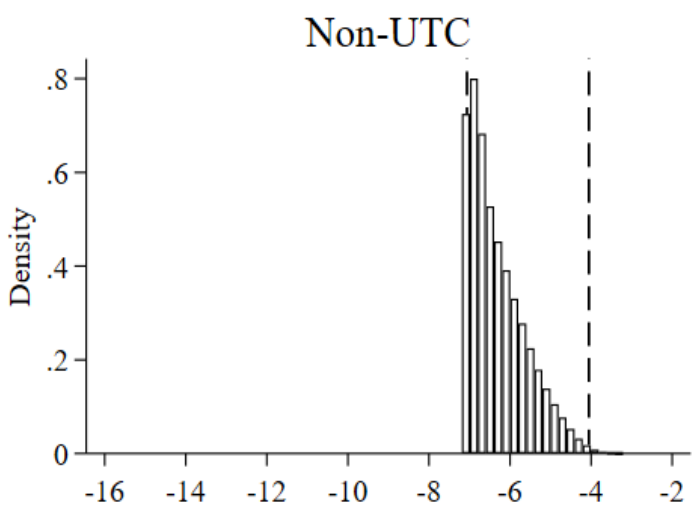

UTC

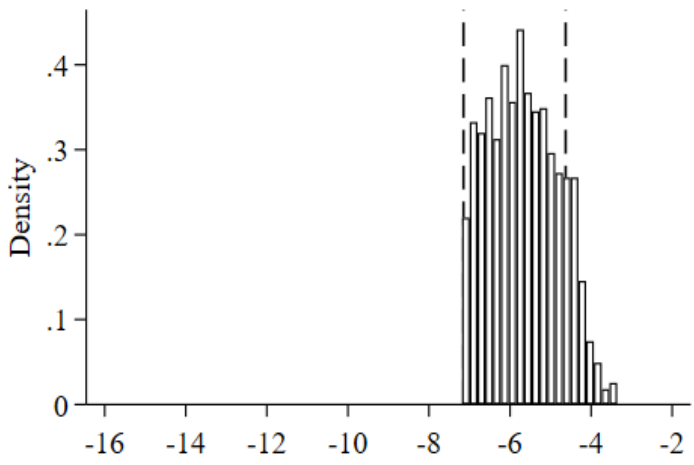

Notes: These Figures plot the distribution of the linearized propensity score for UTC and non-UTC students in Year 10. The first column shows the distribution in the initial sample. The second column shows the distribution in the trimmed sample. In each graph, the vertical bars mark the 2nd and 98th percentiles of the distribution in the opposite group. We compute the propensity score following the procedure outlined by Imbens and Rubin (2015). We trim the sample following the approach of Crump et al. (2009) and discard all the Year 10 students whose propensity score is lower than 0.000751. 
Figure 5a: First stage coefficients (Year 10)

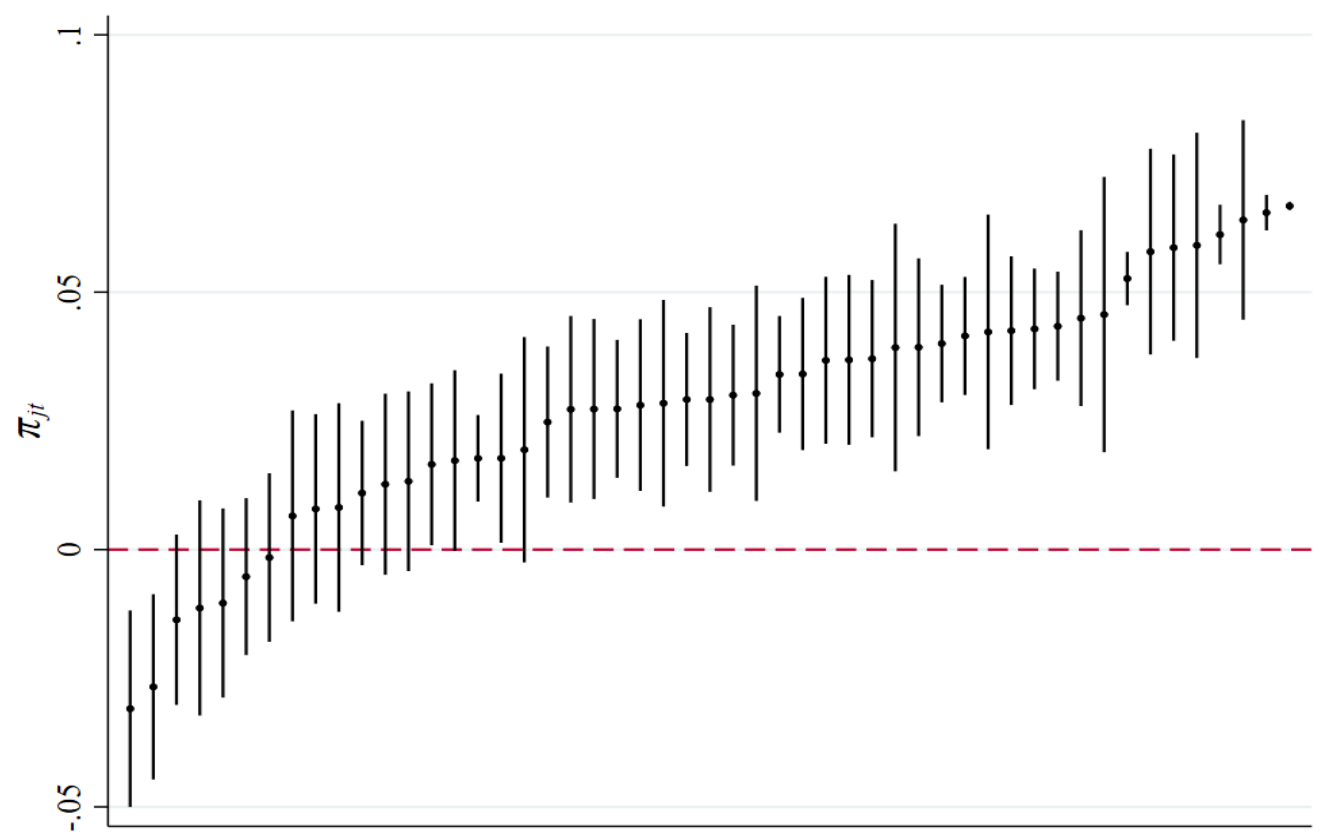

Figure 5b: First stage coefficients (Year 12)

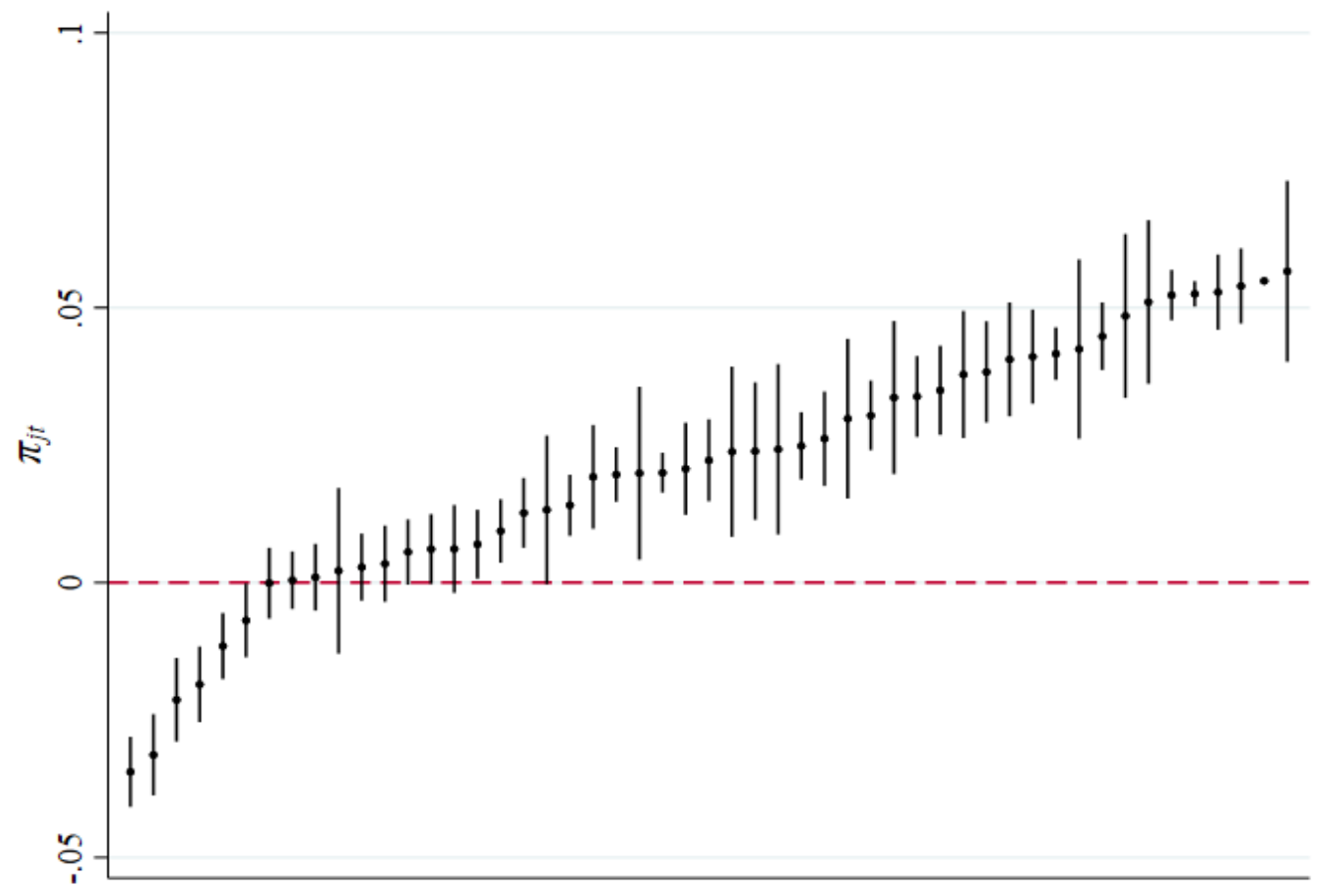

Notes: These figures present first-stage results. We regress an indicator for UTC enrolment on controls for prior attainment at age 11, gender, ethnicity, whether eligible for free school meals, and whether English is spoken as a first language, cohort effects, UTC-by-distance effects, and our set of instruments: the interactions between cohort and UTCby-distance effects. The regression for Year 12 students also controls for GCSE test scores. These graphs plot the coefficients $\left(\pi_{j t}\right)$ of the instruments. Coefficients are sorted by increasing magnitude alongside the corresponding $95 \%$ confidence intervals. The top panel plots coefficients for Year 10 students, while the bottom panel plots coefficients for Year 12 students. Two coefficients in the figures have barely visible confidence intervals: this is because the standard errors are 0.0004 and 0.0002 in Figure 5a and 5b respectively. in the first stage regression equations on the probability of enrolling in a UTC in Year 10 and Year 12 respectively (equation 2). Coefficients are sorted by increasing magnitude alongside the corresponding $95 \%$ CI. Two coefficients in the figures have barely visible CIs: this is because the standard errors are 0.0004 and 0.0002 in Figure 5a and 5b respectively. 
Table 2: Instruments balance test

\begin{tabular}{|c|c|c|c|c|c|c|c|c|c|c|}
\hline & \multicolumn{2}{|c|}{$\begin{array}{l}\text { Eligible } \\
\text { for FSM }\end{array}$} & \multicolumn{2}{|c|}{$\begin{array}{l}\text { KS2 score } \\
\text { in math (std) }\end{array}$} & \multicolumn{2}{|c|}{$\begin{array}{c}\text { KS2 score } \\
\text { in English (std) }\end{array}$} & \multicolumn{2}{|c|}{$\begin{array}{l}\text { KS4 aggregate } \\
\text { score }\end{array}$} & \multicolumn{2}{|c|}{$\begin{array}{l}\text { Propensity } \\
\text { score }\end{array}$} \\
\hline & $(1)$ & $(2)$ & (3) & $(4)$ & $(5)$ & $(6)$ & $(7)$ & $(8)$ & (9) & $(10)$ \\
\hline & \multicolumn{10}{|c|}{ I. Year 10 entrants } \\
\hline UTC enrolment & $\begin{array}{c}0.012 \\
(0.017)\end{array}$ & $\begin{array}{c}0.004 \\
(0.017)\end{array}$ & $\begin{array}{l}-0.135 \\
(0.073)\end{array}$ & $\begin{array}{l}-0.047 \\
(0.040)\end{array}$ & $\begin{array}{l}-0.116 \\
(0.069)\end{array}$ & $\begin{array}{l}-0.042 \\
(0.041)\end{array}$ & & & $\begin{array}{l}-0.000 \\
(0.000)\end{array}$ & $\begin{array}{l}-0.000 \\
(0.000)\end{array}$ \\
\hline \multirow[t]{2}{*}{$\mathrm{N}$} & $1,165,202$ & $1,165,202$ & $1,165,202$ & $1,165,202$ & $1,165,202$ & $1,165,202$ & & & $1,165,202$ & $1,165,202$ \\
\hline & \multicolumn{10}{|c|}{ II. Year 12 entrants } \\
\hline UTC enrolment & $\begin{array}{l}-0.018 \\
(0.019)\end{array}$ & $\begin{array}{l}-0.022 \\
(0.019)\end{array}$ & $\begin{array}{l}0.021 \\
(0.066)\end{array}$ & $\begin{array}{l}0.009 \\
(0.040)\end{array}$ & $\begin{array}{l}0.026 \\
(0.084)\end{array}$ & $\begin{array}{l}0.025 \\
(0.051)\end{array}$ & $\begin{array}{l}-0.024 \\
(0.049)\end{array}$ & $\begin{array}{l}-0.048 \\
(0.027)\end{array}$ & $\begin{array}{l}-0.0001 \\
(0.0001)\end{array}$ & $\begin{array}{l}-0.0001 \\
(0.0001)\end{array}$ \\
\hline $\mathrm{N}$ & $1,051,451$ & $1,051,451$ & $1,051,451$ & $1,051,451$ & $1,051,451$ & $1,051,451$ & $1,051,451$ & $1,051,451$ & $1,051,451$ & $1,051,451$ \\
\hline Other demographics & No & Yes & No & Yes & No & Yes & Yes & Yes & Yes & Yes \\
\hline
\end{tabular}

Notes: This table reports 2SLS estimates of the effect of enrolling in a UTC on a set of pre-determined characteristics (columns 1 to 8 ) and on the propensity score (columns 9 to 10). The instruments are a set of interactions between cohorts, UTC and distance. Regressions include the following controls: cohort fixed effects, distance and UTC interactions. Other demographics include gender, ethnicity, English as first language, eligibility to free meals at school, standardised primary school English and Math test scores. All regressions are weighted using inverse propensity scores. Standard errors are clustered at the UTC level. Significance level: ${ }^{*} \mathrm{p}<0.050,{ }^{* *} \mathrm{p}<0.010,{ }^{* * *} \mathrm{p}<0.001$ 
Table 3: UTC effect for students who enter at age 14 (Year 10)

\begin{tabular}{|c|c|c|c|c|}
\hline & $\begin{array}{l}\text { Baseline } \\
\text { average }\end{array}$ & $\begin{array}{c}\text { Raw difference } \\
\text { btw UTC and } \\
\text { non-UTC }\end{array}$ & OLS & 2SLS \\
\hline Key Stage 4 outcomes & (1) & (2) & (3) & (4) \\
\hline Achieved Five GCSEs & 0.547 & $\begin{array}{c}-0.183 * * * \\
(0.028)\end{array}$ & $\begin{array}{c}-0.189 * * * \\
(0.024)\end{array}$ & $\begin{array}{c}-0.261 * * * \\
(0.055)\end{array}$ \\
\hline Achieved Level 2 in English & 0.612 & $\begin{array}{c}-0.198 * * * \\
(0.031)\end{array}$ & $\begin{array}{c}-0.158 * * * \\
(0.024)\end{array}$ & $\begin{array}{c}-0.142 * * * \\
(0.052)\end{array}$ \\
\hline Achieved Level 2 in Math & 0.667 & $\begin{array}{c}-0.099 * * \\
(0.038)\end{array}$ & $\begin{array}{c}-0.085 * * * \\
(0.021)\end{array}$ & $\begin{array}{l}-0.063^{*} \\
(0.036)\end{array}$ \\
\hline Achieved Level 2 in Science & 0.571 & $\begin{array}{l}-0.063 \\
(0.041)\end{array}$ & $\begin{array}{l}-0.055 \\
(0.039)\end{array}$ & $\begin{array}{c}0.021 \\
(0.073)\end{array}$ \\
\hline Achieved 2 "good" science GCSEs & 0.528 & $\begin{array}{c}-0.164 * * * \\
(0.041)\end{array}$ & $\begin{array}{c}-0.129 * * * \\
(0.040)\end{array}$ & $\begin{array}{c}-0.083 \\
(0.071)\end{array}$ \\
\hline $\mathrm{N}$ & & $3,348,357$ & $1,165,201$ & $1,165,201$ \\
\hline Controls & & No & Yes & Yes \\
\hline
\end{tabular}

Notes: In this table, column (1) reports the baseline average in the trimmed sample used for the estimation; column (2) reports the raw difference between UTC and non-UTC students in the untrimmed sample estimated using unweighted OLS; columns (3) and (4) report OLS and 2SLS estimates of the effect of enrolling in a UTC in Year 10 on Key Stage 4 outcomes (end of secondary school examinations). Each cell reports the coefficient from a separate regression. The instruments are a set of interactions between cohorts, UTCs, and distance. Both specifications include the following controls: cohort fixed effects, distance and distance squared, distance and UTC interactions, gender, ethnicity, English as first language, eligibility to free meals at school, standardised primary school English and Math test scores. Specifications use the trimmed sample and are weighted using inverse propensity scores. Standard errors are clustered at the UTC level. Significance level: ${ }^{*} \mathrm{p}<0.050,{ }^{* *} \mathrm{p}<0.010,{ }^{* * *}$ $\mathrm{p}<0.001$. 
Table 4: UTC effect for students who enter at age 16 (Year 12)

\begin{tabular}{|c|c|c|c|c|}
\hline & $\begin{array}{l}\text { Baseline } \\
\text { average }\end{array}$ & $\begin{array}{c}\text { Raw difference } \\
\text { btw UTC and } \\
\text { non-UTC }\end{array}$ & OLS & 2SLS \\
\hline Post- 16 outcomes & $(1)$ & $(2)$ & (3) & (4) \\
\hline \multicolumn{5}{|l|}{ Academic qualifications (Level 3) } \\
\hline Entered at least one A-Level & 0.617 & $\begin{array}{c}0.116 * * * \\
(0.036)\end{array}$ & $\begin{array}{c}0.114 * * * \\
(0.031)\end{array}$ & $\begin{array}{c}0.096 \\
(0.068)\end{array}$ \\
\hline Achieved at least one A-Level & 0.576 & $\begin{array}{l}-0.032 \\
(0.039)\end{array}$ & $\begin{array}{l}-0.012 \\
(0.030)\end{array}$ & $\begin{array}{c}0.047 \\
(0.071)\end{array}$ \\
\hline \multicolumn{5}{|l|}{ Vocational qualifications (Level 3) } \\
\hline Entered a qualification & 0.566 & $\begin{array}{c}0.242 * * * \\
(0.031)\end{array}$ & $\begin{array}{c}0.217 * * * \\
(0.029)\end{array}$ & $\begin{array}{c}0.218^{* * *} * \\
(0.052)\end{array}$ \\
\hline Achieved a qualification & 0.482 & $\begin{array}{c}0.250 * * * \\
(0.031)\end{array}$ & $\begin{array}{c}0.227 * * * \\
(0.033)\end{array}$ & $\begin{array}{c}0.256^{* * *} \\
(0.057)\end{array}$ \\
\hline STEM qualification (Level 3) & & & & \\
\hline Entered a qualification & 0.523 & $\begin{array}{c}0.295 * * * \\
(0.061)\end{array}$ & $\begin{array}{c}0.266 * * * \\
(0.051)\end{array}$ & $\begin{array}{c}0.247 * * * \\
(0.070)\end{array}$ \\
\hline Achieved a qualification & 0.433 & $\begin{array}{c}0.248 * * * \\
(0.059)\end{array}$ & $\begin{array}{c}0.233 * * * \\
(0.051)\end{array}$ & $\begin{array}{c}0.245^{* * *} \\
(0.067)\end{array}$ \\
\hline Started an apprenticeship & 0.230 & $\begin{array}{c}0.026 \\
(0.025)\end{array}$ & $\begin{array}{c}0.056^{* *} \\
(0.025)\end{array}$ & $\begin{array}{l}0.144^{*} \\
(0.080)\end{array}$ \\
\hline with local UTC partner & 0.007 & $\begin{array}{c}0.012 * * * \\
(0.004)\end{array}$ & $\begin{array}{c}0.012 * * \\
(0.006)\end{array}$ & $\begin{array}{c}0.041 * * \\
(0.019)\end{array}$ \\
\hline $\mathrm{N}$ & & $1,039,722$ & $1,039,722$ & $1,039,722$ \\
\hline Controls: & & No & Yes & Yes \\
\hline
\end{tabular}

Notes: In this table, column (1) reports the baseline average value of each outcome in the trimmed sample used for the estimation; column (2) reports the raw difference between UTC and non-UTC students in the untrimmed sample estimated using unweighted OLS; columns (3) and (4) report OLS and 2SLS estimates of the effect of enrolling in a UTC in Year 12 on post-16 education outcomes. Each cell reports the coefficient from a separate regression. The instruments are a set of interactions of cohorts, UTC and distance. Both specifications include the following controls: cohort fixed effects, distance and distance squared, distance and UTC interactions, gender, ethnicity, English as first language, eligibility to free meals at school, standardised primary school English and Math test scores and Key Stage 4 point score. Specifications use the trimmed sample and are weighted using inverse propensity scores. Standard errors are clustered at the UTC level. Significance level: ${ }^{*} \mathrm{p}<0.050,{ }^{* *} \mathrm{p}<$ $0.010, * * * p<0.001$. 
Table 5: UTC effect on higher education and labour market outcomes

\begin{tabular}{|c|c|c|c|c|c|}
\hline & $\begin{array}{c}\text { Baseline } \\
\text { average }\end{array}$ & $\begin{array}{c}\text { Raw difference } \\
\text { btw UTC and } \\
\text { non-UTC }\end{array}$ & OLS & & $\mathrm{N}$ \\
\hline Post-18 outcomes (1 year) & $(1)$ & $(2)$ & $(3)$ & $(4)$ & $(5)$ \\
\hline In education at age 19 & 0.711 & $\begin{array}{c}0.017 \\
(0.028)\end{array}$ & $\begin{array}{c}0.000 \\
(0.032)\end{array}$ & $\begin{array}{c}-0.031 \\
(0.055)\end{array}$ & 468,894 \\
\hline Started university degree & 0.296 & $\begin{array}{c}-0.073 * * \\
(0.035)\end{array}$ & $\begin{array}{c}-0.048 \\
(0.029)\end{array}$ & $\begin{array}{c}0.043 \\
(0.051)\end{array}$ & 468,894 \\
\hline Started a STEM university degree & 0.068 & $\begin{array}{c}0.096 * * * \\
(0.027)\end{array}$ & $\begin{array}{c}0.098 * * * \\
(0.027)\end{array}$ & $\begin{array}{c}0.183 * * * \\
(0.038)\end{array}$ & 468,894 \\
\hline Not in education, training or employment (NEET) & 0.072 & $\begin{array}{c}-0.030 * * * \\
(0.009)\end{array}$ & $\begin{array}{c}-0.016 \\
(0.012)\end{array}$ & $\begin{array}{c}-0.027 * * \\
(0.012)\end{array}$ & 468,894 \\
\hline Log annual earnings after one year & 4536.6 & $\begin{array}{c}0.341 * * * \\
(0.087)\end{array}$ & $\begin{array}{c}-0.097 \\
(0.187) \\
\end{array}$ & $\begin{array}{c}0.227 \\
(0.379) \\
\end{array}$ & 97,497 \\
\hline Controls & & No & Yes & Yes & \\
\hline
\end{tabular}

Notes: In this table, column (1) reports the baseline average in the trimmed sample used for the estimation; column (2) reports the raw difference in the untrimmed sample estimated using unweighted OLS; columns (3) and (4) report OLS and 2SLS estimates of the effect of enrolling in a UTC in Year 12 on higher education and labour market outcomes. Each cell reports the coefficient from a separate regression. The instruments are a set of interactions of cohorts, UTC and distance. Both specifications include the following controls: cohort fixed effects, distance and distance squared plus flexible distance and UTC interactions, gender, ethnicity, English as first language, eligibility to free meals at school, standardised primary school English and Math test scores and Key Stage 4 point score. Log annual earnings are measured in 2010 prices and the estimation sample for this outcome includes only students who are not observed in any type of education. Standard errors are clustered at the UTC level. Significance level: ${ }^{*} \mathrm{p}<0.050,{ }^{* *} \mathrm{p}<0.010, * * * \mathrm{p}<0.001$. 
Table 6: UTC compliers' characteristics

\begin{tabular}{lccc}
\hline \hline & Year 10 & Year 12 & Difference (2) - (1) \\
\cline { 2 - 4 } Male & $(1)$ & $(2)$ & $(3)$ \\
& $0.827^{* * *}$ & $0.843^{* * *}$ & 0.016 \\
White British & $(0.051)$ & $(0.051)$ & \\
& $0.813^{* * *}$ & $0.829 * * *$ & 0.016 \\
English at home & $(0.054)$ & $(0.054)$ & \\
& $1.010^{* * *}$ & $0.955^{* * *}$ & -0.055 \\
FSM eligible & $(0.034)$ & $(0.024)$ & -0.04 \\
& $0.072 * * *$ & 0.032 & \\
KS2 math score (stand) & $(0.027)$ & $(0.022)$ & 0.369 \\
& -0.009 & $0.369^{* * *}$ & \\
KS2 English score (stand) & $(0.050)$ & $(0.063)$ & 0.329 \\
\hline $\mathrm{N}$ & $-0.248^{* * *}$ & 0.089 & \\
\hline \hline
\end{tabular}

Notes: This table reports the estimated mean of compliers' characteristics for Year 10 and Year 12 entrants. We estimate the compliers' average characteristics using equation (3). The dependent variable is an interaction term between a student i's characteristic and an indicator for whether she is enrolled in the UTC in Year 10 (or 12 respectively). The right-hand-side contains an indicator for whether a student is enrolled in the UTC in Year 10 (or 12 respectively), which we instrument using a set of triple interactions between the cohorts, UTC, and distance variables. The coefficient of the instrumented UTC effect measures the average characteristics among compliers enrolled in a UTC. Both specifications include the following controls (unless they appear on the left-hand side): cohort fixed effects, distance, distance squared plus flexible distance and UTC interactions, gender, ethnicity, English as first language, eligibility to free meals at school, standardised primary school English and Math test scores and Key Stage 4 point score. Specifications are weighted using inverse propensity scores. Standard errors are clustered at the UTC level. Significance level: ${ }^{*} \mathrm{p}<0.050,{ }^{* *} \mathrm{p}<0.010,{ }^{* * *} \mathrm{p}<0.001$. 
Table 7: UTC effect (for students who enter at age 14) under compliers comparability

\begin{tabular}{lcccc}
\hline \hline & $\begin{array}{c}\text { Level 2 } \\
\text { English }\end{array}$ & $\begin{array}{c}\text { Level 2 } \\
\text { math }\end{array}$ & $\begin{array}{c}\text { Level 2 } \\
\text { science }\end{array}$ & $\begin{array}{c}\text { Five } \\
\text { GCSEs } \\
\text { A-C }\end{array}$ \\
\cline { 2 - 5 } Original UTC effect & $(1)$ & $(2)$ & $(3)$ & $(4)$ \\
\hline & $-0.142^{* * *}$ & $-0.063^{*}$ & 0.021 & $-0.261^{* * *}$ \\
& $(0.052)$ & $(0.036)$ & $(0.073)$ & $(0.055)$ \\
\hline
\end{tabular}

Panel A. Heterogenous and counterfactual effect based on KS2 score in math (std)

Diff in baseline score btw Y12 and Y10 students

0.369

\begin{tabular}{rcccc} 
UTC heterogenous effect & 0.320 & 0.062 & $0.636^{* * *}$ & $0.449^{* *}$ \\
$\begin{array}{r}\text { (Coefficient of the UTC interaction term) } \\
(0.247)\end{array}$ & $(0.165)$ & $(0.235)$ & $(0.184)$ \\
$\begin{array}{r}\text { UTC effect with no diff in baseline score } \\
\text { (Interaction x Difference) }\end{array}$ & -0.022 & -0.037 & 0.256 & -0.094 \\
\hline
\end{tabular}

Panel B. Heterogenous and counterfactual effect based on KS2 score in English (std)

Diff in baseline score btw Y12 and Y10 students

0.329

\begin{tabular}{rcccc} 
UTC heterogenous effect & $0.378^{*}$ & 0.179 & $0.412^{* * *}$ & $0.240^{*}$ \\
$\begin{array}{r}\text { (Coefficient of the UTC interaction term) } \\
(0.207)\end{array}$ & $(0.139)$ & $(0.134)$ & $(0.131)$ \\
$\begin{array}{r}\text { UTC effect with no diff in baseline score } \\
\text { (Interaction x Difference) }\end{array}$ & -0.016 & -0.001 & 0.157 & -0.181 \\
\hline
\end{tabular}

Notes: The top part of this table reports the effect of UTC enrolment on GCSE outcomes (as reported in column (4) of Table 3). The rows "UTC heterogenous effect" report the coefficients of an interaction term between UTC enrolment and (standardised) Key Stage 2 score from an augmented version of the 2SLS regression equation. Both UTC enrolment and its interactions are instrumented in the same way as in Equation (2). Finally, the row "UTC effect with no diff in baseline score" reports what the effect of UTC enrolment in Year 10 would be if we assumed that Year 10 UTC entrants looked like Year 12 entrants in terms of attainment in math and English. This is obtained by multiplying the differences reported in "Diff in baseline score btw Y12 and Y10 students" by the interaction coefficients reported in "UTC heterogenous effect" and adding this to the original effect. This assumes that we can alter students' prior attainment in math and English without simultaneously changing other characteristics. Significance level: $* \mathrm{p}<0.050,{ }^{* *} \mathrm{p}<0.010,{ }^{* * *} \mathrm{p}<0.001$. 

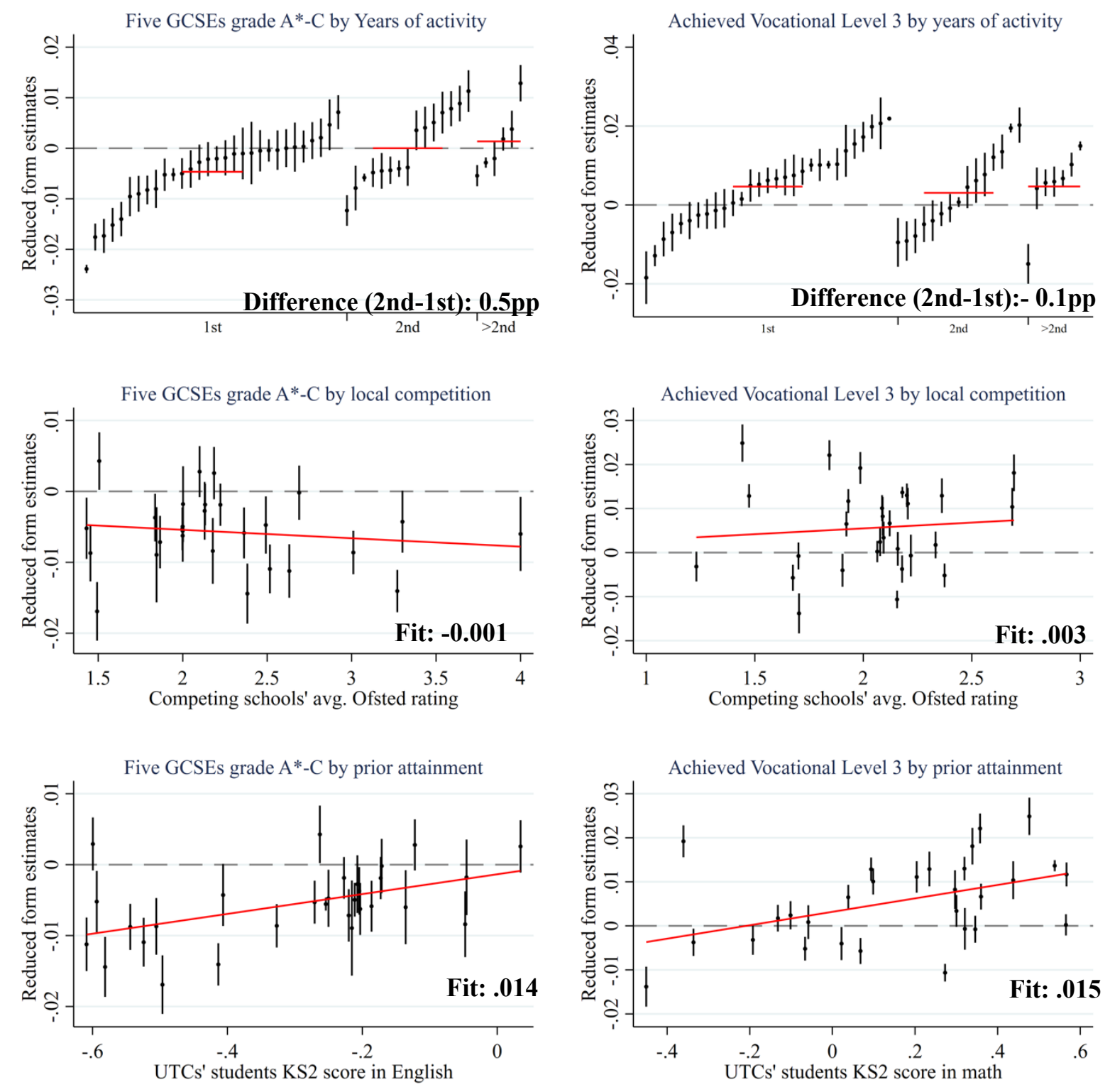

Notes: These graphs plot the coefficients of reduced form regressions of outcomes at Year 10 (left) and Year 12 (right) against some UTC characteristics. All regressions are weighted using the inverse propensity score. Reported 95\% CI are based on standard errors clustered at the UTC level. TOP: These graphs report the coefficients of the triple UTC-by-year-by-distance interactions represented in equation 1 grouped by years since a given UTC has been open in the given academic year; red horizontal lines represent the coefficients' average by years of activity. The difference in the average effect between the second and first year of activity is of $0.5 \mathrm{pp}$ in the probability of achieving 5 GCSEs (left) and $-0.1 \mathrm{pp}$ in the probability of achieving Vocational Level 3. MIDDLE: These graphs report the coefficient of the triple interactions in a simplified version of equation 1 where instead of having an interaction with each year, for each UTC, we have only one interaction with an indicator for when the UTC was open: this gives us only one instrument (and reduced form coefficient) per UTC. The coefficients are plotted against the average OFSTED rating (on a 1-4 scale) for schools and FE colleges within $2 \mathrm{~km}$ (left) and $5 \mathrm{~km}$ (right) of a UTC. The red lines represent the fit of a linear regression. One unit increase in the average quality (rating) of neighbouring schools decreases the reduced form effect of UTC on the probability of achieving 5 GCSEs (left) by $0.1 \mathrm{pp}$ and increases the probability of achieving Vocational Level 3 (right) by 0.3pp. BOTTOM: These graphs plot the coefficients of the triple interactions from equation 4 against the average UTC students' end-of-primary-school standardised test score in English. The red lines represent the fit of a linear regression. One standard deviation increase in students' English test score increases the reduce form effect of UTCs on the probability of achieving 5 GCSEs (left) by $1.4 \mathrm{pp}$ and on the probability of achieving Vocational Level 3 by $1.5 \mathrm{pp}$. 


\section{Appendix A: Trimming method}

Following Imbens and Rubin (2015) and Crump et al. (2009), we estimate the propensity score for UTC enrolment and use it to trim the sample by dropping observations with a probability of enrolling in a UTC that is close to zero.

As a first step, we estimate the propensity score. We follow the procedure of Imbens and Rubin (2015) which adopts an iterative approach to select the set of covariates entering the propensity score estimation. We do this separately for the two groups of Year 10 and Year 12 entrants. We decide to include a priori students' gender and home-to-UTC distance as they are undoubtedly strong predictors of the probability of enrolling in a UTC (as shown in Table 1). We then proceed by iteratively testing which other covariates would increase the log-likelihood in a logistic regression (using the LR test). This confirms that all the remaining variables considered should be included (i.e indicators for being White British, speaking English at home, being eligible for Free School Meals, standardised test scores at the age of 11, and GCSEs aggregate score for Year 12 entrants). Finally, we follow the same procedure to test for the inclusion of interactions between all the variables mentioned above. The final list of covariates used in the propensity score estimation is reported in Panel A of Table A1. The resulting propensity score distribution (linearised) is plotted separately by UTC enrolment status in the left-side panels of Figure 4 and Figure B1 for Year 10 and Year 12 entrants respectively showing the extent of the unbalance across groups. Using the linearised propensity score $^{44}$ allows us to interpret the unbalance in terms of relative scarcity of treatment units compared to control units in a given portion of the covariates distribution. For example, a linearised score of -10 indicates that there are 22,000 times more non-UTC students than UTC students in that part of the distribution. ${ }^{45}$ From the lower-left plot of Figure 4 it is clear that there are barely any UTC students around that point: any comparison of UTC and non-UTC students would therefore heavily rely on extrapolation.

The trimming procedure intends to mitigate this unbalance by discarding all observations whose propensity score lies outside an interval $[\alpha, 1-\alpha]$ with $\alpha$ determined based on the propensity score distribution in order to minimise the variance of the average treatment effect estimator. In practice, we end up discarding all Year 10 observations whose propensity score is lower than 0.000751 (linearised to -7.193) and all Year 12 observations whose propensity score is lower than 0.000754 (linearised to -7.189). The right-side panels of Figure 4 and Figure B1 plot the resulting propensity score distribution which is considerably better balanced across UTC and non-UTC students. After trimming the sample, we re-estimate the propensity score on the trimmed sample. This is to ensure that the weights we use in the Inverse Propensity Score Weighted OLS and 2SLS regressions are computed on the final trimmed sample. We follow the same procedure described above resulting in a partially different selection of covariates (reported in Panel B of Table A1).

\footnotetext{
${ }^{44}$ The linearized propensity score is defined as $\ln \left(\frac{\operatorname{Pr}(U T C \mid X)}{1-\operatorname{Pr}(U T C \mid X)}\right)$, where $\frac{\operatorname{Pr}(U T C \mid X)}{1-\operatorname{Pr}(U T C \mid X)}$ is the odds ratio. $45 \frac{1}{e^{-10}}=22026=\frac{1-\operatorname{Pr}(U T C \mid X)}{\operatorname{Pr}(U T C \mid X)}$
} 
Table A1: List of propensity score estimation covariates

\begin{tabular}{|c|c|c|}
\hline & Year 10 & Year 12 \\
\hline & \multicolumn{2}{|c|}{ a) Estimation in untrimmed sample } \\
\hline Covariates & $\begin{array}{l}\text { Distance to UTC, Gender, White British, } \\
\text { English-at-home, FSM, math test score, } \\
\text { English test score }\end{array}$ & $\begin{array}{l}\text { Distance to UTC, Gender, White British, English- } \\
\text { at-home, FSM, math test score, English test score, } \\
\text { GCSE aggregate score }\end{array}$ \\
\hline \multirow[t]{2}{*}{$\begin{array}{l}\text { Covariates } \\
\text { interactions }\end{array}$} & $\begin{array}{l}\text { Distance with: White British, English- } \\
\text { at-home, FSM, math test score, } \\
\text { distance. } \\
\text { White British with: English-at-home, } \\
\text { FSM } \\
\text { FSM with: English-at-home, Gender } \\
\text { English test score with: Gender, FSM, } \\
\text { English test score } \\
\text { Math test score: Gender, math test } \\
\text { score. }\end{array}$ & $\begin{array}{l}\text { Distance with: White British, English-at-home, } \\
\text { FSM, GCSEs, distance. } \\
\text { White British with: English-at-home, Gender, } \\
\text { English test score, GCSEs. } \\
\text { English test score with: English-at-home, math } \\
\text { test score, FSM. } \\
\text { Math test score: English-at-home, math test score. } \\
\text { GCSEs aggregate score with: GCSEs. }\end{array}$ \\
\hline & \multicolumn{2}{|c|}{ b) Estimation in trimmed sample } \\
\hline Covariates & $\begin{array}{l}\text { Distance to UTC, Gender, White British, } \\
\text { English-at-home, FSM, math test score, } \\
\text { English test score }\end{array}$ & $\begin{array}{l}\text { Distance to UTC, Gender, White British, English- } \\
\text { at-home, FSM, math test score, English test score, } \\
\text { GCSE aggregate score }\end{array}$ \\
\hline $\begin{array}{l}\text { Covariates } \\
\text { interactions }\end{array}$ & $\begin{array}{l}\text { Distance with: Gender, White British, } \\
\text { English-at-home, FSM, math test score, } \\
\text { distance. } \\
\text { White British with: English-at-home, } \\
\text { FSM } \\
\text { FSM with: English-at-home, Gender, } \\
\text { English test score } \\
\text { English test score with: Gender, } \\
\text { English test score } \\
\text { Math test score: Gender, math test } \\
\text { score. }\end{array}$ & $\begin{array}{l}\text { Distance with: White British, English-at-home, } \\
\text { FSM, GCSE. } \\
\text { White British with: English-at-home } \\
\text { FSM with: English test score, GCSEs } \\
\text { English test score with: Gender, English-at-home, } \\
\text { math test score, English test score } \\
\text { Math test score: English-at-home, GCSEs, math } \\
\text { test score. } \\
\text { GCSEs aggregate score with: Gender, English-at- } \\
\text { home GCSEs. }\end{array}$ \\
\hline
\end{tabular}


Figure B1: Propensity score distribution (Year 12)

Initial sample

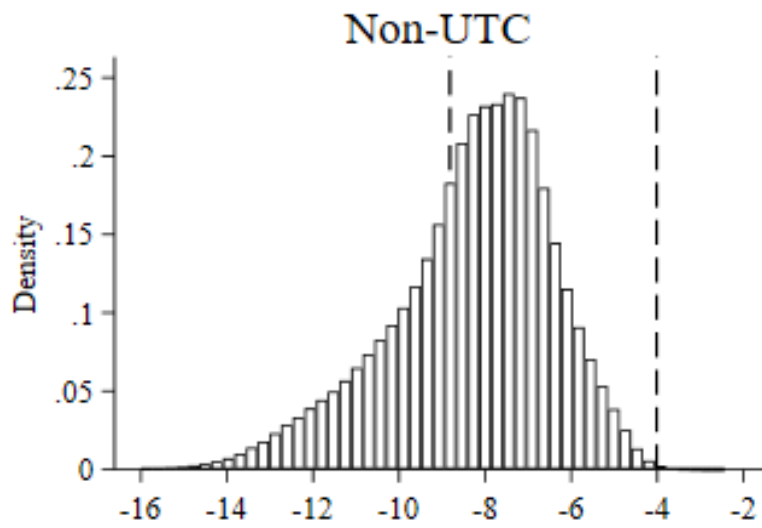

UTC

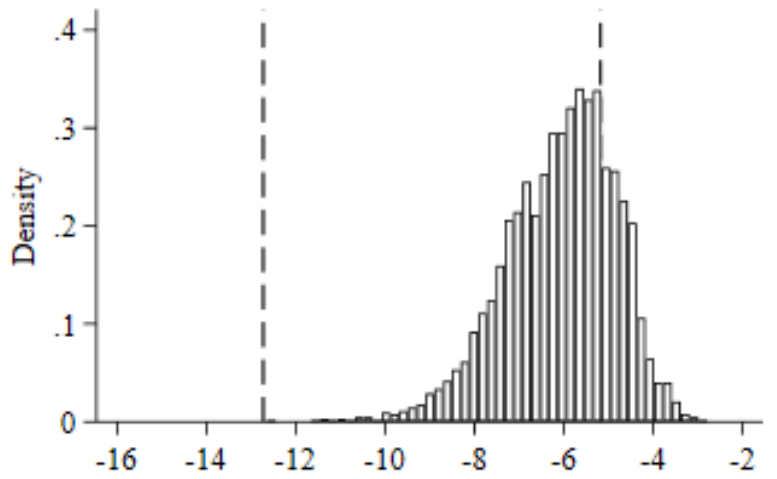

Trimmed sample

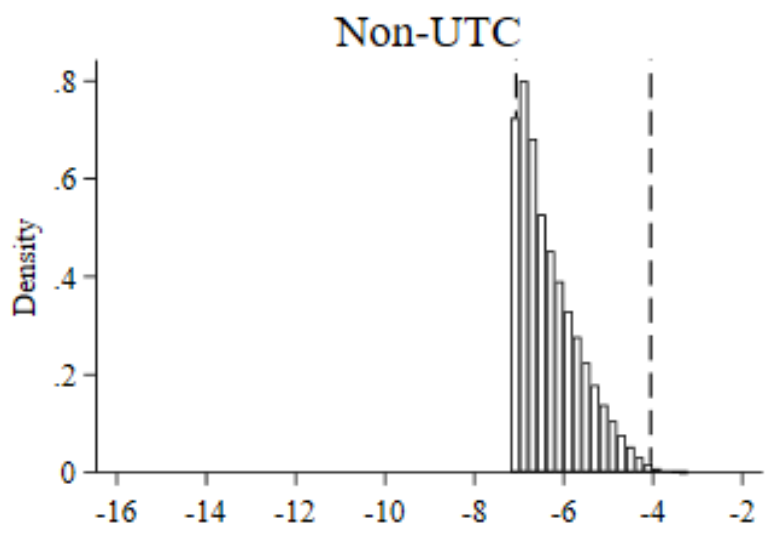

UTC

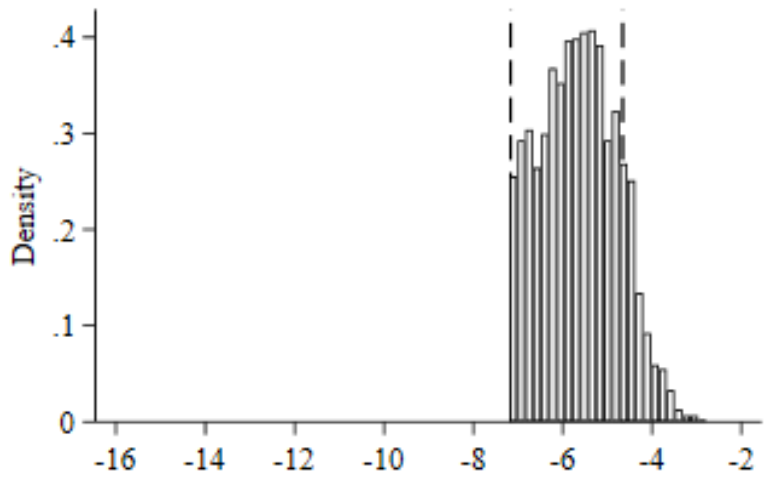

Notes: These Figures plot the distribution of the linearized propensity score for UTC and non-UTC students in Year 12. The first column shows the distribution in the initial sample. The second column shows the distribution in the trimmed sample. In each graph, the vertical bars mark the 2nd and 98th percentiles of the distribution in the opposite group. We compute the propensity score following the procedure outlined by Imbens and Rubin (2015). We trim the sample following the approach of Crump et al. (2009) and discard all the Year 12 students whose propensity score is lower than 0.000754 
Table B1: UTC effect for students who enter at age 14 (Year 10)

\begin{tabular}{|c|c|c|c|c|c|c|c|}
\hline \multirow[b]{4}{*}{ Key Stage 4 outcomes } & \multirow{4}{*}{$\begin{array}{c}\text { Baseline } \\
\text { average }\end{array}$} & \multicolumn{4}{|c|}{ Geographic distance } & \multirow{2}{*}{\multicolumn{2}{|c|}{ Travel-to-school distance }} \\
\hline & & \multicolumn{2}{|c|}{ Linear } & \multicolumn{2}{|c|}{ Flexible polynomial } & & \\
\hline & & OLS & 2SLS & OLS & 2SLS & OLS & 2SLS \\
\hline & & (2) & (3) & (4) & (5) & (6) & (7) \\
\hline Achieved Five GCSEs & 0.547 & $\begin{array}{c}-0.189 * * * \\
(0.024)\end{array}$ & $\begin{array}{c}-0.261 * * * \\
(0.055)\end{array}$ & $\begin{array}{c}-0.188 * * * \\
(0.024)\end{array}$ & $\begin{array}{l}-0.263 * * * \\
(0.037)\end{array}$ & $\begin{array}{c}-0.187 * * * \\
(0.025)\end{array}$ & $\begin{array}{l}-0.229 * * * \\
(0.057)\end{array}$ \\
\hline Achieved Level 2 in English & 0.612 & $\begin{array}{c}-0.158 * * * \\
(0.024)\end{array}$ & $\begin{array}{c}-0.142 * * * \\
(0.052)\end{array}$ & $\begin{array}{c}-0.159 * * * \\
(0.024)\end{array}$ & $\begin{array}{c}-0.164 * * * \\
(0.043)\end{array}$ & $\begin{array}{c}-0.164 * * * \\
(0.025)\end{array}$ & $\begin{array}{c}-0.127 * * * \\
(0.049)\end{array}$ \\
\hline Achieved Level 2 in Math & 0.667 & $\begin{array}{l}-0.085 * * * \\
(0.021)\end{array}$ & $\begin{array}{l}-0.063^{*} \\
(0.036)\end{array}$ & $\begin{array}{c}-0.086 * * * \\
(0.021)\end{array}$ & $\begin{array}{l}-0.094 * * * \\
(0.026)\end{array}$ & $\begin{array}{c}-0.083 * * * \\
(0.021)\end{array}$ & $\begin{array}{l}-0.036 \\
(0.036)\end{array}$ \\
\hline Achieved Level 2 in Science & 0.571 & $\begin{array}{l}-0.055 \\
(0.039)\end{array}$ & $\begin{array}{c}0.021 \\
(0.073)\end{array}$ & $\begin{array}{l}-0.055 \\
(0.039)\end{array}$ & $\begin{array}{l}-0.054 \\
(0.063)\end{array}$ & $\begin{array}{l}-0.055 \\
(0.038)\end{array}$ & $\begin{array}{c}0.053 \\
(0.062)\end{array}$ \\
\hline $\begin{array}{l}\text { Achieved } 2 \text { "good" science } \\
\text { GCSEs }\end{array}$ & 0.528 & $\begin{array}{c}-0.129 * * * \\
(0.040)\end{array}$ & $\begin{array}{l}-0.083 \\
(0.071)\end{array}$ & $\begin{array}{c}-0.129 * * * \\
(0.040)\end{array}$ & $\begin{array}{c}-0.149 * * \\
(0.059)\end{array}$ & $\begin{array}{c}-0.132 * * * \\
(0.040)\end{array}$ & $\begin{array}{l}-0.073 \\
(0.061)\end{array}$ \\
\hline $\mathrm{N}$ & $1,165,201$ & $1,165,201$ & $1,165,201$ & $1,165,201$ & $1,165,201$ & $1,165,201$ & $1,165,201$ \\
\hline
\end{tabular}

Notes: Column (1) reports the baseline average in the trimmed sample used for the estimation while columns (2) to (7) reports OLS and 2SLS estimates of the effect of enrolling in a UTC in Year 10 on Key Stage 4 outcomes (end of secondary school examinations). Each cell reports the coefficient from a separate regression. The instruments are a set of interactions between cohorts, UTCs, and distance. Both specifications include the following controls: cohort fixed effects, distance and distance squared, distance and UTC interactions, gender, ethnicity, English as first language, eligibility to free meals at school, standardised primary school English and Math test scores. Specifications use the trimmed sample and are weighted using inverse propensity scores. In the specification reported in column (4) and (5), we adopt a flexible definition of distance in which, for each UTC separately, we use the distance polynomial that best approximates the relationship between enrolment. Specification in columns (6) and (7) is equivalent to the main one but using travel-to-school distance. Standard errors are clustered at the UTC level. Significance level: $* p<0.050, * * p<0.010, * * * p<0.001$. 
Table B2: UTC effect for students who enter at age 16 (Year 12)

\begin{tabular}{|c|c|c|c|c|c|c|c|}
\hline \multirow[b]{4}{*}{ Post-16 outcomes } & \multirow{4}{*}{$\begin{array}{c}\begin{array}{c}\text { Baseline } \\
\text { average }\end{array} \\
(1)\end{array}$} & \multicolumn{4}{|c|}{ Geographic distance } & \multirow{2}{*}{\multicolumn{2}{|c|}{$\begin{array}{l}\text { Travel-to-school } \\
\text { distance }\end{array}$}} \\
\hline & & \multicolumn{2}{|c|}{ Linear } & \multicolumn{2}{|c|}{ Flexible polynomial } & & \\
\hline & & OLS & 2SLS & OLS & 2SLS & OLS & 2SLS \\
\hline & & $(2)$ & (3) & (4) & $(5)$ & $(6)$ & (7) \\
\hline Entered one A-Level & 0.617 & $\begin{array}{c}0.114 * * * \\
(0.031)\end{array}$ & $\begin{array}{c}0.096 \\
(0.068)\end{array}$ & $\begin{array}{c}0.115^{* * *} \\
(0.031)\end{array}$ & $\begin{array}{c}0.122 * * \\
(0.061)\end{array}$ & $\begin{array}{c}0.109 * * * \\
(0.030)\end{array}$ & $\begin{array}{c}0.049 \\
(0.068)\end{array}$ \\
\hline Achieved one A-Level & 0.576 & $\begin{array}{l}-0.012 \\
(0.030)\end{array}$ & $\begin{array}{c}0.047 \\
(0.071)\end{array}$ & $\begin{array}{l}-0.009 \\
(0.030)\end{array}$ & $\begin{array}{c}0.070 \\
(0.058)\end{array}$ & $\begin{array}{l}-0.030 \\
(0.029)\end{array}$ & $\begin{array}{l}-0.095 \\
(0.069)\end{array}$ \\
\hline Entered Vocational Level 3 & 0.566 & $\begin{array}{c}0.217 * * * \\
(0.029)\end{array}$ & $\begin{array}{c}0.218 * * * \\
(0.052)\end{array}$ & $\begin{array}{c}0.217 * * * \\
(0.029)\end{array}$ & $\begin{array}{c}0.227 * * * \\
(0.042)\end{array}$ & $\begin{array}{c}0.211 * * * \\
(0.030)\end{array}$ & $\begin{array}{c}0.196 * * * \\
(0.067)\end{array}$ \\
\hline Achieved Vocational Level 3 & 0.482 & $\begin{array}{c}0.227 * * * \\
(0.033)\end{array}$ & $\begin{array}{c}0.256^{* * * *} \\
(0.057)\end{array}$ & $\begin{array}{c}0.227 * * * \\
(0.033)\end{array}$ & $\begin{array}{c}0.278 * * * \\
(0.043)\end{array}$ & $\begin{array}{c}0.215^{* * * *} \\
(0.036)\end{array}$ & $\begin{array}{c}0.198 * * \\
(0.080)\end{array}$ \\
\hline Entered any STEM Level 3 & 0.523 & $\begin{array}{c}0.266^{* * * *} \\
(0.051)\end{array}$ & $\begin{array}{c}0.247 * * * \\
(0.070)\end{array}$ & $\begin{array}{c}0.264 * * * \\
(0.052)\end{array}$ & $\begin{array}{c}0.229 * * * \\
(0.076)\end{array}$ & $\begin{array}{c}0.255^{* * *} \\
(0.058)\end{array}$ & $\begin{array}{c}0.188 * * \\
(0.096)\end{array}$ \\
\hline Achieved any STEM Level 3 & 0.433 & $\begin{array}{c}0.233^{* * * *} \\
(0.051)\end{array}$ & $\begin{array}{c}0.245^{* * *} \\
(0.067)\end{array}$ & $\begin{array}{c}0.233 * * * \\
(0.051)\end{array}$ & $\begin{array}{c}0.223 * * * \\
(0.073)\end{array}$ & $\begin{array}{c}0.221 * * * \\
(0.056)\end{array}$ & $\begin{array}{c}0.180 * * \\
(0.091)\end{array}$ \\
\hline Started an apprenticeship & 0.230 & $\begin{array}{c}0.056^{* *} \\
(0.025)\end{array}$ & $\begin{array}{l}0.144 * \\
(0.080)\end{array}$ & $\begin{array}{c}0.056^{* *} \\
(0.025)\end{array}$ & $\begin{array}{l}0.113^{*} \\
(0.069)\end{array}$ & $\begin{array}{c}0.063 * * \\
(0.026)\end{array}$ & $\begin{array}{c}0.155^{* *} \\
(0.076)\end{array}$ \\
\hline $\begin{array}{l}\text { Started apprent. with local UTC } \\
\text { partner }\end{array}$ & 0.007 & $\begin{array}{c}0.012 * * \\
(0.006)\end{array}$ & $\begin{array}{l}0.041^{* *} \\
(0.019)\end{array}$ & $\begin{array}{c}0.012 * * \\
(0.006)\end{array}$ & $\begin{array}{c}0.032 * * \\
(0.016)\end{array}$ & $\begin{array}{c}0.013^{* *} \\
(0.006)\end{array}$ & $\begin{array}{c}0.036 \\
(0.022)\end{array}$ \\
\hline $\mathrm{N}$ & $1,039,722$ & $1,039,722$ & $1,039,722$ & $1,039,722$ & $1,039,722$ & $1,039,722$ & $1,039,722$ \\
\hline
\end{tabular}

Notes: Column (1) reports the baseline average value of each outcome in the trimmed sample used for the estimation while columns (2) to (7) report OLS and 2SLS estimates of the effect of enrolling in a UTC in Year 12 on post-16 education outcomes. Each cell reports the coefficient from a separate regression. The instruments are a set of interactions of cohorts, UTC and distance. Both specifications include the following controls: cohort fixed effects, distance and distance squared, distance and UTC interactions, gender, ethnicity, English as first language, eligibility to free meals at school, standardised primary school English and Math test scores and Key Stage 4 point score. Specifications use the trimmed sample and are weighted using inverse propensity scores. Standard errors are clustered at the UTC level. In the specification reported in column (4) and (5) we adopt a flexible definition of distance in which, for each UTC separately, we use the distance polynomial that best approximates the relationship between enrolment. Specification in columns (6) and (7) is equivalent to the main one but using travel-to-school distance. Significance level: $* \mathrm{p}<0.050, * * \mathrm{p}<0.010, * * * \mathrm{p}<0.001$. 
Table B3: UTC effect on higher education and labour market outcomes

\begin{tabular}{|c|c|c|c|c|c|c|c|c|}
\hline \multirow[b]{4}{*}{ Post-18 outcomes (1 year) } & \multirow{4}{*}{$\begin{array}{c}\text { Baseline } \\
\text { average }\end{array}$} & \multicolumn{4}{|c|}{ Geographic distance } & \multirow{2}{*}{\multicolumn{2}{|c|}{$\begin{array}{c}\text { Travel-to-school } \\
\text { distance }\end{array}$}} & \multirow{4}{*}{$\frac{\mathrm{N}}{(6)}$} \\
\hline & & \multicolumn{2}{|c|}{ Linear } & \multicolumn{2}{|c|}{ Flexible polynomial } & & & \\
\hline & & OLS & 2SLS & OLS & 2SLS & OLS & 2SLS & \\
\hline & & (2) & (3) & (4) & (5) & (6) & (7) & \\
\hline In education at age 19 & 0.711 & $\begin{array}{c}0.000 \\
(0.032)\end{array}$ & $\begin{array}{l}-0.031 \\
(0.055)\end{array}$ & $\begin{array}{c}0.001 \\
(0.032)\end{array}$ & $\begin{array}{l}-0.050 \\
(0.055)\end{array}$ & $\begin{array}{c}0.013 \\
(0.029)\end{array}$ & $\begin{array}{l}-0.013 \\
(0.044)\end{array}$ & 468,894 \\
\hline Started university degree & 0.296 & $\begin{array}{c}-0.048 \\
(0.029)\end{array}$ & $\begin{array}{c}0.043 \\
(0.051)\end{array}$ & $\begin{array}{c}-0.048 \\
(0.030)\end{array}$ & $\begin{array}{c}0.028 \\
(0.048)\end{array}$ & $\begin{array}{c}-0.043 \\
(0.029)\end{array}$ & $\begin{array}{c}0.099 \\
(0.087)\end{array}$ & 468,894 \\
\hline Started a STEM university degree & 0.068 & $\begin{array}{c}0.098 * * * \\
(0.027)\end{array}$ & $\begin{array}{c}0.183 * * * \\
(0.038)\end{array}$ & $\begin{array}{c}0.098 * * * \\
(0.027)\end{array}$ & $\begin{array}{c}0.171 * * * \\
(0.037)\end{array}$ & $\begin{array}{c}0.105^{* * *} \\
(0.030)\end{array}$ & $\begin{array}{c}0.246^{* * *} \\
(0.070)\end{array}$ & 468,894 \\
\hline Not in education, training or employment (NEET) & 0.072 & $\begin{array}{c}-0.016 \\
(0.012)\end{array}$ & $\begin{array}{c}-0.027 * * \\
(0.012)\end{array}$ & $\begin{array}{l}-0.017 \\
(0.012)\end{array}$ & $\begin{array}{l}-0.027 \\
(0.020)\end{array}$ & $\begin{array}{c}-0.021^{* *} \\
(0.009)\end{array}$ & $\begin{array}{c}-0.034 * * \\
(0.014)\end{array}$ & 468,894 \\
\hline Log annual earnings after one year & 4542.4 & $\begin{array}{c}-0.097 \\
(0.187)\end{array}$ & $\begin{array}{c}0.227 \\
(0.379)\end{array}$ & $\begin{array}{c}-0.094 \\
(0.189)\end{array}$ & $\begin{array}{c}0.243 \\
(0.316)\end{array}$ & $\begin{array}{c}-0.040 \\
(0.172)\end{array}$ & $\begin{array}{c}0.314 \\
(0.349)\end{array}$ & 97,497 \\
\hline
\end{tabular}

Notes: Column (1) reports the baseline average in the trimmed sample used for the estimation while columns (2) to (7) report OLS and 2SLS estimates of the effect of enrolling in a UTC in Year 12 on higher education and labour market outcomes. Each cell reports the coefficient from a separate regression. The instruments are a set of interactions of cohorts, UTC and distance. Both specifications include the following controls: cohort fixed effects, distance and distance squared plus flexible distance and UTC interactions, gender, ethnicity, English as first language, eligibility to free meals at school, standardised primary school English and Math test scores and Key Stage 4 point score. Log annual earnings are measured in 2010 prices and the estimation sample for this outcome includes only students who are not observed in any type of education. Standard errors are clustered at the UTC level. In the specification reported in column (4) and (5) we adopt a flexible definition of distance in which, for each UTC separately, we use the distance polynomial that best approximates the relationship between enrolment. Specification in columns (6) and (7) is equivalent to the main one but using travelto-school distance. Log annual earnings are measured in 2010 prices and the estimation sample for this outcome includes only students who are not observed in any type of education. Standard errors clustered at the UTC level. Significance level: ${ }^{*} \mathrm{p}<0.050,{ }^{*} * \mathrm{p}<0.010,{ }^{*} * \mathrm{p}<0.001$. 
Table B4: UTC effect using Nearest Neighbour matched sample Students who enter at age 14 (Year 10)

\begin{tabular}{|c|c|c|c|c|}
\hline \multirow[b]{3}{*}{ Key Stage 4 outcomes } & \multicolumn{2}{|c|}{ "Main specification } & \multicolumn{2}{|c|}{ Matched sample } \\
\hline & OLS & 2SLS & OLS & 2SLS \\
\hline & $(1)$ & $(2)$ & (3) & (4) \\
\hline Achieved Five GCSEs & $\begin{array}{c}-0.189 * * * \\
(0.024)\end{array}$ & $\begin{array}{c}-0.261 * * * \\
(0.055)\end{array}$ & $\begin{array}{c}-0.162 * * * \\
(0.025)\end{array}$ & $\begin{array}{c}-0.254 * * * \\
(0.062)\end{array}$ \\
\hline Achieved Level 2 in English & $\begin{array}{c}-0.158 * * * \\
(0.024)\end{array}$ & $\begin{array}{c}-0.142 * * * \\
(0.052)\end{array}$ & $\begin{array}{c}-0.128 * * * \\
(0.024)\end{array}$ & $\begin{array}{c}-0.145^{* * *} \\
(0.052)\end{array}$ \\
\hline Achieved Level 2 in Math & $\begin{array}{c}-0.085 * * * \\
(0.021)\end{array}$ & $\begin{array}{l}-0.063 * \\
(0.036)\end{array}$ & $\begin{array}{c}-0.064 * * * \\
(0.020)\end{array}$ & $\begin{array}{l}-0.049 \\
(0.046)\end{array}$ \\
\hline Achieved Level 2 in Science & $\begin{array}{l}-0.055 \\
(0.039)\end{array}$ & $\begin{array}{c}0.021 \\
(0.073)\end{array}$ & $\begin{array}{l}-0.033 \\
(0.034)\end{array}$ & $\begin{array}{c}0.024 \\
(0.054)\end{array}$ \\
\hline $\begin{array}{l}\text { Achieved } 2 \text { "good" science } \\
\text { GCSEs }\end{array}$ & $\begin{array}{c}-0.129 * * * \\
(0.040)\end{array}$ & $\begin{array}{l}-0.083 \\
(0.071)\end{array}$ & $\begin{array}{c}-0.128 * * * \\
(0.033)\end{array}$ & $\begin{array}{l}-0.095 \\
(0.062)\end{array}$ \\
\hline $\mathrm{N}$ & $1,165,201$ & $1,165,201$ & 5,746 & 5,746 \\
\hline
\end{tabular}

Notes: Columns (1) and (2) report OLS and 2SLS estimates of the effect of enrolling in a UTC in Year 10 on Key Stage 4 education outcomes obtained using the main specification with inverse probability score weighting (as reported in Table 3); columns (3) and (4) report OLS and 2SLS estimates of the same effect in a sample [N=5746] obtained matching each treated unit to its nearest neighbour based on the estimated propensity score (without replacement). Each cell reports the coefficient from a separate regression. Both specifications include the following controls: cohort fixed effects, distance, distance squared, distance and UTC interactions, gender, ethnicity, English as first language, eligibility to free meals at school, standardised primary school English and Math test scores and Key Stage 4 point score. Excluded instruments are a set of interactions of cohorts, UTC and distance. Achieved outcomes are conditional on entry. Standard errors are clustered at the UTC level. Significance level: $* \mathrm{p}<0.050, * * \mathrm{p}<0.010, * * * \mathrm{p}<0.001$. 
Table B5: UTC effect using Nearest Neighbour matched sample Students who enter at age 16 (Year 12)

\begin{tabular}{|c|c|c|c|c|}
\hline \multirow[b]{3}{*}{ Post-16 outcomes } & \multicolumn{2}{|c|}{ Main specification } & \multicolumn{2}{|c|}{ Matched sample } \\
\hline & OLS & 2SLS & OLS & 2SLS \\
\hline & (1) & (2) & (3) & (4) \\
\hline Entered at least one A-Level & $\begin{array}{l}0.114 * * * \\
(0.031)\end{array}$ & $\begin{array}{l}0.096 \\
(0.068)\end{array}$ & $\begin{array}{l}0.134 * * * \\
(0.034)\end{array}$ & $\begin{array}{l}0.066 \\
(0.082)\end{array}$ \\
\hline Achieved at least on A-Level & $\begin{array}{l}-0.012 \\
(0.030)\end{array}$ & $\begin{array}{l}0.047 \\
(0.071)\end{array}$ & $\begin{array}{l}0.004 \\
(0.026)\end{array}$ & $\begin{array}{l}-0.033 \\
(0.070)\end{array}$ \\
\hline Entered Vocational Level 3 & $\begin{array}{l}0.217 * * * \\
(0.029)\end{array}$ & $\begin{array}{l}0.218 * * * \\
(0.052)\end{array}$ & $\begin{array}{l}0.197 * * * \\
(0.031)\end{array}$ & $\begin{array}{l}0.258^{* * *} \\
(0.043)\end{array}$ \\
\hline Achieved Vocational Level 3 & $\begin{array}{l}0.227 * * * \\
(0.033)\end{array}$ & $\begin{array}{l}0.256^{* * * *} \\
(0.057)\end{array}$ & $\begin{array}{l}0.216^{* * *} \\
(0.028)\end{array}$ & $\begin{array}{l}0.315^{* * *} \\
(0.050)\end{array}$ \\
\hline Entered any STEM Level 3 & $\begin{array}{l}0.266^{* * *} \\
(0.051)\end{array}$ & $\begin{array}{l}0.247 * * * \\
(0.070)\end{array}$ & $\begin{array}{l}0.317^{* * *} \\
(0.038)\end{array}$ & $\begin{array}{l}0.243 * * * \\
(0.046)\end{array}$ \\
\hline Achieved any STEM Level 3 & $\begin{array}{l}0.233 * * * \\
(0.051)\end{array}$ & $\begin{array}{l}0.245^{* * *} \\
(0.067)\end{array}$ & $\begin{array}{l}0.284 * * * \\
(0.038)\end{array}$ & $\begin{array}{l}0.243 * * * \\
(0.044)\end{array}$ \\
\hline Started an apprenticeship & $\begin{array}{l}0.056^{* *} \\
(0.025)\end{array}$ & $\begin{array}{l}0.144^{*} \\
(0.080)\end{array}$ & $\begin{array}{l}0.060^{* *} \\
(0.024)\end{array}$ & $\begin{array}{l}0.146^{* * *} \\
(0.054)\end{array}$ \\
\hline Started apprent. with local UTC partner & $\begin{array}{c}0.012^{* *} \\
(0.006)\end{array}$ & $\begin{array}{c}0.041^{* *} \\
(0.019)\end{array}$ & $\begin{array}{c}0.014^{* *} \\
(0.005)\end{array}$ & $\begin{array}{c}0.028^{* *} \\
(0.014)\end{array}$ \\
\hline $\mathrm{N}$ & $1,039,722$ & $1,039,722$ & 5,721 & 5,721 \\
\hline
\end{tabular}

Notes: Columns (1) and (2) report OLS and 2SLS estimates of the effect of enrolling in a UTC in Year 12 on post-16 education outcomes obtained using the main specification with inverse probability score weighting (as reported in Table 4); columns (3) and (4) report OLS and 2SLS estimates of the same effect in a sample [ $\mathrm{N}=4996]$ obtained matching each treated unit to its nearest neighbour based on the estimated propensity score (without replacement). Each cell reports the coefficient from a separate regression. Both specifications include the following controls: cohort fixed effects, distance, distance squared, distance and UTC interactions, gender, ethnicity, English as first language, eligibility to free meals at school, standardised primary school English and Math test scores and Key Stage 4 point score. Excluded instruments are a set of interactions of cohorts, UTC and distance. Achieved outcomes are conditional on entry. Standard errors clustered at the UTC level. Significance level: ${ }^{*} \mathrm{p}<0.050,{ }^{* *} \mathrm{p}<0.010,{ }^{* * *} \mathrm{p}<0.001$. 
Table B6: UTC effect using Nearest Neighbour matched sample Higher education and labour market outcomes

\begin{tabular}{|c|c|c|c|c|}
\hline \multirow[b]{3}{*}{ Post- 18 outcomes ( 1 year) } & \multicolumn{2}{|c|}{ Main specification } & \multicolumn{2}{|c|}{ Matched sample } \\
\hline & OLS & 2SLS & OLS & 2SLS \\
\hline & (1) & (2) & (3) & (4) \\
\hline In education at age 19 & $\begin{array}{l}0.000 \\
(0.032)\end{array}$ & $\begin{array}{l}-0.031 \\
(0.055)\end{array}$ & $\begin{array}{l}-0.041 \\
(0.039)\end{array}$ & $\begin{array}{l}0.037 \\
(0.103)\end{array}$ \\
\hline Started university degree & $\begin{array}{l}-0.048 \\
(0.029)\end{array}$ & $\begin{array}{l}0.043 \\
(0.051)\end{array}$ & $\begin{array}{l}-0.061 \\
(0.058)\end{array}$ & $\begin{array}{l}0.127 \\
(0.145)\end{array}$ \\
\hline Started a STEM university degree & $\begin{array}{l}0.098 * * * \\
(0.027)\end{array}$ & $\begin{array}{l}0.183 * * * \\
(0.038)\end{array}$ & $\begin{array}{l}0.136^{* * *} \\
(0.030)\end{array}$ & $\begin{array}{l}0.247 * * \\
(0.111)\end{array}$ \\
\hline Not in education, training or employment (NEET) & $\begin{array}{l}-0.016 \\
(0.012)\end{array}$ & $\begin{array}{l}-0.027 * * \\
(0.012)\end{array}$ & $\begin{array}{l}-0.014 \\
(0.020)\end{array}$ & $\begin{array}{l}-0.017 \\
(0.029)\end{array}$ \\
\hline Log annual earnings after one year & $\begin{array}{l}-0.097 \\
(0.187) \\
\end{array}$ & $\begin{array}{l}0.227 \\
(0.379) \\
\end{array}$ & $\begin{array}{l}-0.364 \\
(0.256) \\
\end{array}$ & $\begin{array}{l}-0.306 \\
(0.390) \\
\end{array}$ \\
\hline
\end{tabular}

Notes: Columns (1) and (2) report OLS and 2SLS estimates of the effect of enrolling in a UTC in Year 12 on post-18 education and labour market outcomes obtained using the main specification with inverse probability score weighting (as reported in Table 6); columns (3) and (4) report OLS and 2SLS estimates of the same effect in a sample [N=1996] obtained matching each treated unit to its nearest neighbour based on the estimated propensity score (without replacement). Each cell reports the coefficient from a separate regression. Both specifications include the following controls: cohort fixed effects, distance and distance squared, plus distance and UTC interactions, gender, ethnicity, English as first language, eligibility to free meals at school, standardised primary school English and Math test scores and Key Stage 4 point score. Excluded instruments are a set of interactions of cohorts, UTC and distance. Log annual earnings are measured in 2010 prices and the estimation sample for this outcome includes only students who are not observed in any type of education. Standard errors are clustered at the UTC level. Significance level: $* \mathrm{p}<0.050, * * \mathrm{p}<0.010, * * * \mathrm{p}<0.001$. 
Table B7: Summary of heterogeneity analysis

\begin{tabular}{|c|c|c|c|c|}
\hline & & \multirow{2}{*}{$\frac{\text { Year } 10}{5 \text { GCSEs with grade } A^{*-C}}$} & \multicolumn{2}{|c|}{ Year 12} \\
\hline & & & Achieved Vocational Level 3 & Started Apprenticeship \\
\hline Years of activity & Difference (2nd-1 st year): & $0.5 \mathrm{pp}$ & $-0.1 \mathrm{pp}$ & $0.1 \mathrm{pp}$ \\
\hline Local competition & One unit increase in quality: & $-0.1 \mathrm{pp}$ & $0.3 p p$ & $-0.4 \mathrm{pp}$ \\
\hline Prior attainment in English & One SD increase in average test score: & $1.4 \mathrm{pp}$ & $1.5 \mathrm{pp}$ & $-0.04 \mathrm{pp}$ \\
\hline Prior attainment in math & One SD increase in average test score: & $1 \mathrm{pp}$ & $1.5 \mathrm{pp}$ & $-0.02 \mathrm{pp}$ \\
\hline
\end{tabular}

Notes: This table summarizes the results reported in Figure 6 and Figure A2 in the appendix. 
Figure B2: Heterogeneous effects on apprenticeship
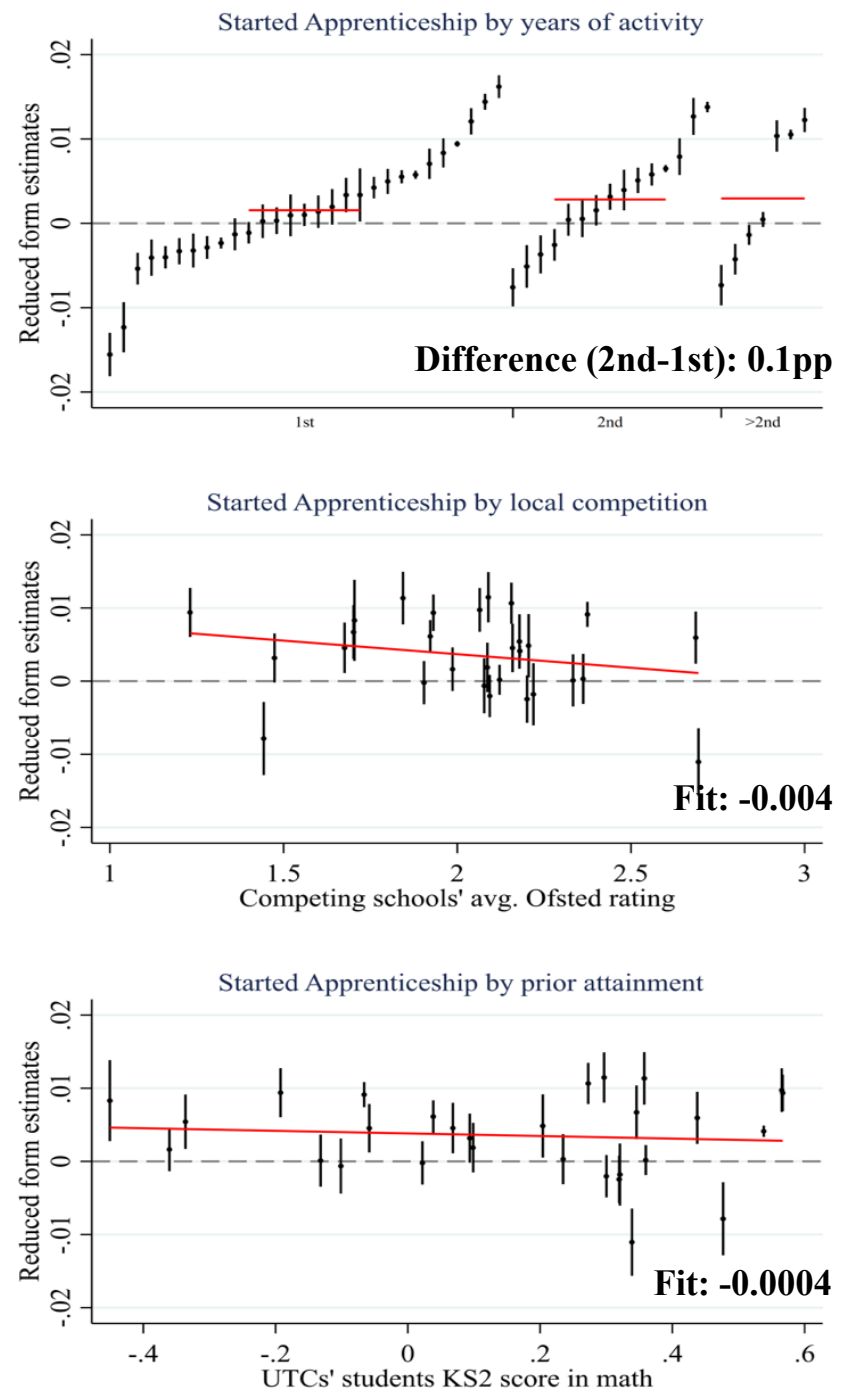

Notes: These graphs plot the coefficients of reduced form regressions on the probability of starting an apprenticeship against some UTC characteristics. All regressions are weighted using the inverse propensity score. Reported 95\% CI are based on standard errors clustered at the UTC level. TOP: This graph reports the coefficients of the triple UTC-by-year-by-distance interactions represented in equation 1 grouped by years since a given UTC has been open in the given academic year; red horizontal lines represent the coefficients' average by years of activity. The difference in the average effect between the second and first year of activity is of $0.1 \mathrm{pp}$ in the probability of starting an apprenticeship. MIDDLE: This graph reports the coefficient of the triple interactions in a simplified version of equation 1 where instead of having an interaction with each year, for each UTC, we have only one interaction with an indicator for when the UTC was open: this gives us only one instrument (and reduced form coefficient) per UTC. The coefficients are plotted against the average OFSTED rating (on a 1-4 scale) for schools and FE colleges within $5 \mathrm{~km}$ of a UTC. The red line represents the fit of a linear regression. One unit increase in the average quality (rating) of neighbouring schools decreases the reduced form effect of UTC on the probability of starting an apprenticeship by $0.4 \mathrm{pp}$. BOTTOM: This graph plots the coefficients of the triple interactions in the modified version of equation 1 against the average UTC students' end-of-primary-school standardised test score in English. The red line represents the fit of a linear regression. One standard deviation increase in students' English test score decreases the reduce form effect of UTCs on the probability of starting an apprenticeship by $0.04 \mathrm{pp}$. 